\title{
On the Efficiency of Baroclinic Eddy Growth and How It Reduces the North Pacific Storm-Track Intensity in Midwinter
}

\author{
SEBASTIAN SCHEMM \\ Institute for Atmospheric and Climate Science, ETH Zürich, Zurich, Switzerland \\ GWENDAL RIVIÈRE \\ LMD/IPSL, École Normale Supérieure, PSL Research University, Sorbonne Université, École Polytechnique, CNRS, Paris, France
}

(Manuscript received 13 February 2019, in final form 26 August 2019)

\begin{abstract}
This study investigates the efficiency of baroclinic eddy growth in an effort to better understand the suppression of the North Pacific storm-track intensity in winter. The efficiency of baroclinic eddy growth depends on the magnitude and orientation of the vertical tilt of the eddy geopotential isolines. The eddy efficiency is maximized if the orientation of the vertical tilt creates an eddy heat flux that aligns with the mean baroclinicity (defined as minus the temperature gradient divided by a stratification parameter) and if the magnitude of the vertical tilt is neither too strong nor too weak. The eddy efficiency is, in contrast to most other eddy measures, independent of the eddy amplitude and thus useful for improving our mechanistic understanding of the effective eddy growth. During the midwinter suppression, the eddy efficiency is reduced north of $40^{\circ} \mathrm{N}$ over a region upstream of the main storm track, and baroclinic growth is reduced despite a maximum in baroclinicity. Eulerian diagnostics and feature tracking suggest that the reduction in eddy efficiency is due to a stronger poleward tilt with height of eddies entering the Pacific through the northern seeding branch, which results in a more eastward-oriented eddy heat flux and a reduced alignment with the baroclinicity. The stronger poleward tilt with height is constrained by the eddy propagation direction, which is more equatorward when the subtropical jet moves equatorward in winter. In addition, the westward tilt with height is too strong. South of $40^{\circ} \mathrm{N}$, the eddy efficiency increases during midwinter but in a region far away from the main storm track.
\end{abstract}

\section{Introduction}

Baroclinic instability has long been recognized as the main type of fluid dynamic instability that gives rise to the growth and propagation of extratropical cyclones (Charney 1947; Eady 1949; Lindzen and Farrell 1980). The extratropical regions that encompass the preferred tracks of extratropical cyclone propagation are commonly referred to as storm tracks (Chang et al. 2002). Factors that control baroclinicity, a measure for the potential growth of extratropical cyclones, and factors that control the character of cyclone life cycles are active fields of research (e.g., Harnik and Chang 2004; Rivière 2009; Booth et al. 2012; Michel and Rivière 2014; Coronel et al. 2015; Novak et al. 2015; Mbengue and Schneider 2018; Schemm and Schneider 2018, and many others)—see Chang et al. (2002) and Shaw et al. (2016)

Corresponding author: Sebastian Schemm, sebastian.schemm@ env.ethz.ch for reviews. The future development of baroclinicity and processes underlying its variability are key for understanding projected storm-track changes (O'Gorman and Schneider 2008; O'Gorman 2010; Woollings et al. 2012; Harvey et al. 2014). For example, the Arctic amplification has, in principle, the potential to affect storm tracks through changes in baroclinicity (Cohen et al. 2014; Wang et al. 2017; Francis 2017).

However, there are two known examples that appear to fringe the close connection between baroclinicity and storm-track intensity as is suggested by linear theory. The first example is the midwinter suppression of eddy kinetic energy (EKE) over the North Pacific (e.g., Nakamura 1992; Chang 2001; Nakamura and Sampe 2002; Penny et al. 2010; Schemm and Schneider 2018) and the second example is the North Atlantic storm track during the Last Glacial Maximum (LGM) as seen in different climate simulations (e.g., Li and Battisti 2008; Laîné et al. 2009; Rivière et al. 2018). During the midwinter suppression, the North Pacific jet stream is 
strongest, relative to the shoulder seasons, but located far equatorward relative to the regions of highest surface baroclinicity. This meridional displacement between the upper-level jet and the surface baroclinicity has been suspected to play an important role in the formation of the suppression (Nakamura and Sampe 2002; Lachmy and Harnik 2014), in particular because a mild midwinter storm-track reduction appears to emerge also over the North Atlantic during winters with strong subtropical jets (Penny et al. 2013; Afargan and Kaspi 2017) and because the seasonal transition in the jet characteristics reproduces the observed reduction in eddy activity in idealized simulations (Yuval et al. 2018); however, the exact processes limiting the growth of extratropical cyclones in large-scale flow environments with high baroclinicity and strong subtropical jets remain unclear and debated.

The primary dynamical cause for the formation of the midwinter suppression is unknown, and it appears as if different mechanisms are at play over and upstream of the North Pacific storm track. For example, the relative contribution due to a reduced number of downstream propagating upper-level eddies from Asia into the North Pacific has been debated (Penny et al. 2010; Chang and Guo 2011; Penny et al. 2011; Chang and Guo 2012; Penny et al. 2013), but the reduction in the number of shortwave upper-level perturbations does not appear to affect the number of observed surface cyclones, which peak during midwinter (Schemm and Schneider 2018). Idealized modeling suggests that the narrowing of the jet stream makes the North Pacific potentially less unstable to shortwave perturbations entering the storm track from upstream (Harnik and Chang 2004), resulting in reduced eddy growth. Further, the increased group velocity during midwinter, due to a faster jet, can result in eddies propagating too fast across the North Pacific (Chang 2001), resulting in reduced eddy life time (Schemm and Schneider 2018), which limits the potential for perturbations to develop into intense systems (Chang 2001). Indeed, Schemm and Schneider (2018) find a suppression in observed deepening and decay rates along the tracks of surface cyclones and a suppression of the mean EKE per cyclone life cycle. Further idealized modeling studies suggest a potential key role of increased deformation and horizontal jet shear, known as the barotropic governor, in causing a suppression of baroclinic and barotropic eddy growth (James 1987; Nakamura 1993; Harnik and Chang 2004; Deng and Mak 2005). Indeed, observations show that both barotropic and baroclinic EKE generating processes are suppressed (Schemm and Schneider 2018). Diabatic processes have likewise received attention. The seasonal storm-track cycle is not accurately represented in idealized dry simulations but is considerably more realistic when incorporating moist heating (Chang and Zurita-Gotor 2007). Chang (2001) and Chang and Song (2006) find that the contribution by latent heat release to the conversion from the mean available potential energy to the eddy available potential energy is maximized for the North Pacific in fall with a local minimum in winter, while it is of similar magnitude for the North Atlantic throughout fall and winter.

The midwinter suppression appears to affect a wide range of storm-track measures. Eddy heat and potential vorticity fluxes and baroclinic and barotropic conversion into EKE are all affected by the suppression, which typically extends in time and increases in strength at higher altitudes (Schemm and Schneider 2018), which makes it difficult to isolate a leading process that causes storm-track suppression in a high-baroclinicity environment. However, the eddy efficiency, later defined in the paper, is a measure of the ability of the eddies to extract the background flow potential energy and reflects the vertical structure of growing eddies. In contrast to the other eddy measures, it is independent of the eddy amplitude. Our study shows that it is the multiplication between the baroclinicity magnitude and the eddy efficiency that should be considered for understanding the baroclinic growth and not only the baroclinicity magnitude (i.e., the Eady growth rate).

The study is organized as follows: The methodology is introduced in section 2. The definition of an eddy efficiency and eddy total energy tendency, and the relationships between eddy efficiency, eddy diffusivity, and the vertical eddy tilt are presented in detail in section 3. The seasonal cycle of baroclinic conversion and the relevant quantities entering the definition of an eddy efficiency are discussed in section 4 . In section 5 regression maps are used to discuss the evolution of baroclinic conversion and propagation direction of baroclinic waves. The results of the regression maps are complemented in section 6 with results from feature-based tracking and cyclone-centered composites.

\section{Methods and data}

\section{a. Cyclone tracking and data}

This study relies on ERA-Interim data, which are publicly available via ECMWF's archive (http:// apps.ecmwf.int/datasets/). For the detection and tracking of surface cyclones, we make use of the Wernli and Schwierz (2006) algorithm in its latest version (Sprenger et al. 2017). The algorithm performs a contour search in mean sea level pressure (SLP) at intervals of $0.5 \mathrm{hPa}$. All 
grid points inside an outermost closed SLP contour are flagged with 1 , and all grid points outside are flagged with 0 to obtain a cyclone mask. The maximum length of the outermost SLP contour is $7500 \mathrm{~km}$. In a next step the scheme connects the cyclone masks and the corresponding cyclone centers, which are defined as the minimum SLP inside the outermost closed SLP contour, using 6-hourly time steps and ERA-Interim data (Dee et al. 2011) that are interpolated to a $1^{\circ}$ grid. The scheme accepts cyclone tracks if they exist for longer than $24 \mathrm{~h}$. No frequency filtering in time or space is performed. The employed scheme does not identify anticyclones. For a detailed comparison of the algorithm's performance relative to other methods, we refer to Neu et al. (2013). The monthly mean cyclone data are publicly available (http://eraiclim.ethz.ch/) and higher-resolution data on request. The analysis period is 1979-2017.

\section{b. Cyclone-centered and rotated composites}

The computation of cyclone-centered composites involves two types of coordinate transformations. The first transformation minimizes the influence of the poleward converging meridians on the final composite. This transformation into a quasi-equidistant coordinate system is performed by rotating the geographical coordinate system such that the new equator runs through the center of the surface cyclone. The procedure is similar to the one used by some limitedarea numerical weather prediction models, for example, by the operational model of the German (DWD) and Swiss (MeteoSwiss) Weather Services [Consortium for Small-Scale Modeling (COSMO); Steppeler et al. 2003]. In this study, we use a similar procedure as that used by the COSMO model. A detailed description of the implementation is given in Part I, section 2, of the COSMO documentation (which is available at www.cosmo-model.org). In general, transformations of this kind can be performed using the software package Cartographic Projections Library PROJ.4 (PROJ Contributors 2018). The second transformation rotates all fields into the cyclone propagation direction. To this end, we determine the angle between a vector connecting two consecutive positions of the surface cyclone and an eastward pointing vector. The cyclone-centered and rotated composites are limited to a region with a $20^{\circ}$ radius around the surface cyclone center and display the composite mean high-pass-filtered geopotential $\phi^{\prime}$ at different vertical levels. High- and low-pass-filtered components are computed similar as in Rivière et al. (2018) using a 10-day cutoff period. Further relevant quantities, such as the eddy heat flux, baroclinic conversion, or eddy total energy (see next section for details) are derived from the composite-mean $\phi^{\prime}$ using quasigeostrophic scaling, $u^{\prime}=-\left[(1 / f)\left(\partial \phi^{\prime} / \partial y\right)\right], v^{\prime}=(1 / f)\left(\partial \phi^{\prime} / \partial x\right), \theta^{\prime}=$ $-\left[\left(p_{0} / p\right)^{\kappa}(p / R)\left(\partial \phi^{\prime} / \partial p\right)\right]$, with $\kappa=0.286, p_{0}=1000, \mathrm{hPa}$, and $R=287 \mathrm{~J} \mathrm{~kg}^{-1} \mathrm{~K}^{-1}$. This result allows for a direct comparison of the relationships between these quantities. Note that the calculation for individual cases and averaging afterward yields similar conclusions. We use 6-hourly data for all analyses, but for computational reasons the vertical cross sections are limited to 1200 UTC data.

\section{Baroclinic eddy efficiency, eddy total energy, and its relationship with eddy diffusivity}

The eddy total energy is defined as the sum of eddy kinetic energy and the eddy available potential energy (e.g., Lorenz 1955; Orlanski and Katzfey 1991; Chang et al. 2002), which are defined as $K_{e}^{\prime}=(1 / 2) \mathbf{v}^{\prime 2}$ and $P_{e}^{\prime}=(1 / 2 S) \theta^{\prime 2}$, respectively, and where $\mathbf{v}^{\prime 2}=\left(u^{\prime 2}+v^{\prime 2}\right)$ denotes the square of the high-pass-filtered horizontal wind velocity, $\theta^{\prime}$ denotes the high-pass-filtered potential temperature, and $S=-h^{-1}\left(\partial \theta_{R} / \partial p\right)$ the static stability in pressure coordinates, which depends only on pressure. The reference potential temperature $\theta_{R}$ is computed from the climatological mean of each individual month from October to April. It varies with space to take into account local changes in climatological-mean static stability. The scale height is $h=(R / p)\left(p / p_{0}\right)^{R / c_{p}}$, where all variables take on their usual meteorological meaning. Overbars denote the low-pass-filtered part of the flow.

\section{a. Eddy kinetic energy equation}

Tendency equations for eddy kinetic energy and eddy available potential energy can be obtained by multiplying the filtered horizontal primitive momentum equation in isobaric coordinates with the high-pass-filtered horizontal wind velocity to obtain

$$
\begin{aligned}
\frac{\partial K_{e}^{\prime}}{\partial t}= & -\nabla \cdot\left(\mathbf{v} K_{e}^{\prime}+\mathbf{v}_{a}^{\prime} \phi^{\prime}\right)-\frac{\partial}{\partial p}\left(\omega K_{e}^{\prime}+\omega^{\prime} \phi^{\prime}\right) \\
& +\omega^{\prime} \frac{\partial \phi^{\prime}}{\partial p}-\mathbf{v}^{\prime} \cdot\left(\mathbf{v}_{3}^{\prime} \cdot \nabla \overline{\mathbf{v}}\right)+R_{K_{e}},
\end{aligned}
$$

where the residual term is $R_{K_{e}}=\mathbf{v}^{\prime} \cdot\left(\overline{\mathbf{v}_{3} \cdot \nabla \mathbf{v}}-\overline{\mathbf{v}}_{3} \cdot \nabla_{3} \overline{\mathbf{v}}\right)$, $\phi^{\prime}$ the filtered geopotential height, and the subscript " 3 " denotes three-dimensional wind velocities or gradients. The work done by the pressure force $\left(-\mathbf{v}^{\prime} \cdot \nabla \phi^{\prime}\right)$ corresponds to the sum of the three terms $-\left[(\partial / \partial p)\left(\omega^{\prime} \phi^{\prime}\right)\right]+$ $\omega^{\prime}\left(\partial \phi^{\prime} / \partial p\right)-\nabla\left(\mathbf{v}_{a}^{\prime} \phi^{\prime}\right)$, where $\mathbf{v}_{a}^{\prime}$ is the ageostrophic wind. The above equation reduces to the equation presented by Orlanski and Katzfey (1991) if the time filter is replaced by a time average. More details on the derivation are presented in the appendixes. 


\section{b. Eddy available potential energy equation}

The tendency of eddy available potential energy is obtained by multiplying the filtered thermodynamic equation with $\theta^{\prime} / S$ (Drouard et al. 2015) to obtain

$$
\begin{aligned}
\frac{\partial P_{e}^{\prime}}{\partial t}= & -\nabla \cdot\left(\mathbf{v} P_{e}^{\prime}\right)-\omega^{\prime} \frac{\partial \phi^{\prime}}{\partial p}-\frac{1}{S} \theta^{\prime}\left(\mathbf{v}^{\prime} \cdot \nabla \bar{\theta}\right) \\
& -\frac{1}{S} \frac{\partial}{\partial p}\left(\omega \frac{\theta^{\prime 2}}{2}\right)+R_{P_{e}},
\end{aligned}
$$

where the residual term is $R_{P_{e}}=\left(\theta^{\prime} / S\right)\left[\overline{\left(\mathbf{v}_{3} \cdot \nabla \theta\right)}-\overline{\mathbf{v}}_{3} \cdot \nabla_{3} \bar{\theta}\right]$ and nonconservative sources and sinks are neglected. The internal baroclinic conversion, from the eddy potential to the eddy kinetic energy, is $\omega^{\prime}\left(\partial \phi^{\prime} / \partial p\right)$. In case of a constant stratification, the fourth term on the righthand side of Eq. (2) reduces to the vertical convergence of the vertical $P_{e}^{\prime}$ flux. More details on the derivation are presented in the appendixes.

\section{c. Eddy total energy equation}

To obtain a tendency equation for the total eddy energy, defined as $T_{e}^{\prime}=\left(K_{e}^{\prime}+P_{e}^{\prime}\right)$, the two equations are added, which yields

$$
\begin{aligned}
\frac{\partial T_{e}^{\prime}}{\partial t}= & -\nabla \cdot\left(\mathbf{v} T_{e}^{\prime}+\mathbf{v}_{a}^{\prime} \phi^{\prime}\right)-\frac{1}{S} \theta^{\prime}\left(\mathbf{v}^{\prime} \cdot \nabla \bar{\theta}\right)-\mathbf{v}^{\prime} \cdot\left(\mathbf{v}_{3}^{\prime} \cdot \nabla \overline{\mathbf{v}}\right) \\
& -\frac{\partial}{\partial p}\left(\omega K_{e}^{\prime}+\omega^{\prime} \phi^{\prime}\right)-\frac{1}{S} \frac{\partial}{\partial p}\left(\omega \frac{\theta^{\prime 2}}{2}\right)+R_{T_{e}}
\end{aligned}
$$

where the external baroclinic conversion from the mean available potential energy into the eddy total energy is the second term on the right-hand side in Eq. (3). Following Cai and Mak (1990) and Rivière et al. (2018), the external baroclinic conversion can be expressed as a scalar product between baroclinicity and the eddy heat flux,

$$
-\frac{1}{S} \theta^{\prime}\left(\mathbf{v}^{\prime} \cdot \nabla \bar{\theta}\right)=\mathbf{Q}_{s} \cdot \mathbf{B}_{s}
$$

where $\mathbf{Q}_{s}=(1 / \sqrt{S})\left(\mathbf{v}^{\prime} \theta^{\prime}\right)$ is the eddy heat flux normalized by the static stability and $\mathbf{B}_{s}=-[(1 / \sqrt{S}) \nabla \bar{\theta}]$ is the background baroclinicity, which corresponds to minus the time-mean temperature gradient normalized by the static stability and is proportional to the Eady growth rate or the isentropic slope. Note that both vectors are perpendicular to the definitions of vectors $\mathbf{F}$ and $\mathbf{T}$ in Cai and Mak (1990) and $\mathbf{F}$ and $\mathbf{B}_{c}$ in Rivière et al. (2018) to match the climatological heat flux and temperature gradients in the atmosphere.

\section{d. Eddy efficiency: Vertical tilt orientation and magnitude}

The external baroclinic conversion [Eq. (4)] can be expressed as follows,

$$
\mathbf{Q}_{s} \cdot \mathbf{B}_{s}=\left|\mathbf{Q}_{s}\right|\left|\mathbf{B}_{s}\right| \cos \left(\mathbf{Q}_{s}, \mathbf{B}_{s}\right)=T_{e}^{\prime}\left|\mathbf{B}_{s}\right| E_{\mathrm{ff}},
$$

where the eddy efficiency $E_{\mathrm{ff}}$, which consists of the eddy tilt orientation efficiency $E_{\mathrm{ff} \|}$ and eddy tilt magnitude efficiency $E_{\mathrm{ff} \nless}$ (Rivière et al. 2004), is defined as

$$
E_{\mathrm{ff}}=\frac{\left|\mathbf{Q}_{s}\right|}{T_{e}^{\prime}} \cos \left(\mathbf{Q}_{s}, \mathbf{B}_{s}\right)=E_{\mathrm{ff} \|} \cdot E_{\mathrm{ff} \nless} .
$$

Consequently, baroclinic conversion is maximized if $E_{\mathrm{ff} \nless} \equiv \cos \left(\mathbf{Q}_{s}, \mathbf{B}_{s}\right)$, the eddy tilt orientation efficiency, equals one. This is the case when the eddy heat flux is aligned with the mean baroclinicity $\mathbf{B}_{s}$. For an equatorward-oriented temperature gradient, a poleward eddy heat flux maximizes the efficiency of eddies to convert the mean available potential energy into the eddy total energy via baroclinic processes. Quasigeostrophic scaling suggests that a poleward eddy heat flux is associated with eddy geopotential lines that tilt westward with height and an eastward eddy heat flux is associated with eddy geopotential lines that tilt poleward with height. In case of a zonally asymmetric temperature gradient, the meridional eddy tilt with height thus also controls the efficiency of baroclinic conversion. The relationship between the eddy tilt orientation efficiency $\left(E_{\mathrm{ff}} \nless\right)$, the eddy heat flux $\left(\mathbf{Q}_{s}\right)$, the mean baroclinicity $\left(\mathbf{B}_{s}\right)$, and the vertical tilt of a growing eddy is schematically summarized in Fig. 1.

The eddy tilt magnitude efficiency is controlled by

$$
E_{\mathrm{ff} \|} \equiv \frac{\left|\mathbf{Q}_{s}\right|}{T_{e}^{\prime}}=\frac{\sqrt{S^{-1} \theta^{\prime 2}\left(u^{\prime 2}+v^{\prime 2}\right)}}{\left(K_{e}^{\prime}+P_{e}^{\prime}\right)},
$$

which is maximum and equal to one if $K_{e}^{\prime}=P_{e}^{\prime}$. Baroclinic conversion can therefore be less efficient if the westward tilt with height is too strong or too weak [see also Fig. 1 of Rivière and Joly (2006) for further details on this decomposition and Rivière et al. (2004) on the decomposition in height coordinates]. Rather, there is an optimal amplitude of the vertical tilt that corresponds to the phase quadrature of the upper- and lower-level baroclinic wave in idealized models as described in, for example, Davies and Bishop (1994).

The nature of the eddy efficiency differs from other eddy measures, such as the eddy heat flux, eddy momentum flux, eddy kinetic energy, or geopotential 


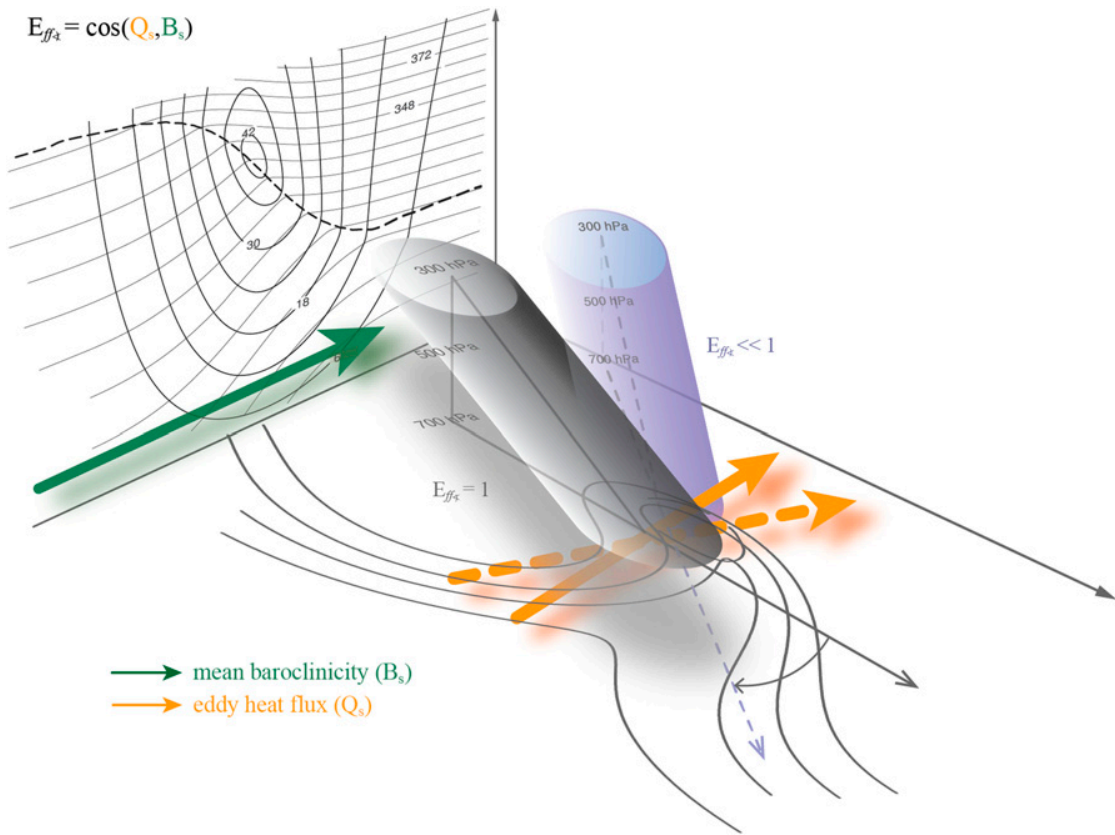

FIG. 1. Eddy tilt orientation efficiency $\left(E_{\mathrm{ff}} \nless\right.$ ): Idealized representation of the relationship between the eddy vertical tilt orientation, the eddy heat flux (orange vectors), and the mean baroclinicity (green vector). A westward-tilted eddy (gray eddy geopotential tube) is associated with a northward eddy heat flux (orange solid vector). In this case, the baroclinic conversion is maximized, because the eddy heat flux aligns with the mean baroclinicity (green vector). The eddy tilt orientation efficiency is one. For a northwestward-tilted eddy (blue eddy geopotential tube), the associated eddy heat flux is northeastward (orange dashed vector). In this case, the alignment between the heat flux and the mean baroclinicity is reduced, which results in a lowered baroclinic conversion, and an eddy tilt orientation efficiency lower than one. In this schematic, the tilt magnitude is not changed. The direction of propagation is indicated by black vectors.

height anomalies, because it is independent of the eddy amplitude. The eddy efficiency relates the mean baroclinicity to the vertical structure of the growing eddy, and thus sits at the transition between measures that characterize the mean background conditions, which are not suppressed during midwinter, and those eddy measures that depend on the eddy amplitude, which are all suppressed during midwinter. Finally, note that the baroclinic conversion divided by the eddy total energy is an important term of the evolution of the eddy total energy growth rate and is reduced to the multiplication of the baroclinicity magnitude by the eddy efficiency. Such a baroclinic growth rate is thus a particularly useful metric to explain differences in eddy amplitude.

\section{e. Relationship between eddy efficiency and eddy diffusivity}

In an effort to better understand present-day variability and future changes of the poleward transports of heat and moisture, studies have investigated changes in storm-track diffusivity (e.g., Caballero and Hanley 2012). Here we briefly discuss the connection between the eddy diffusivity and the eddy efficiency.

Using a semiempirical flux-gradient relationship that connects the time-mean heat flux with the mean baroclinicity, $\overline{\mathbf{Q}}_{s}=D \mathbf{B}_{s}$, allows for relating the time-mean baroclinic growth to an eddy diffusivity times the baroclinicity squared,

$$
\overline{\mathbf{Q}}_{s} \cdot \mathbf{B}_{\mathrm{s}}=D\left|\mathbf{B}_{s}\right|^{2},
$$

where $D$ is the eddy diffusivity [see also Eq. (3) of Lapeyre and Held (2003)]. Consequently, the timemean eddy efficiency can be related to the eddy diffusivity,

$$
\bar{E}_{\mathrm{ff}}=D \frac{\left|\mathbf{B}_{s}\right|}{\overline{T_{e}^{\prime}}} .
$$

The eddy diffusivity in storm tracks is therefore closely connected to the baroclinic eddy efficiency and thus also 
controlled by the mean vertical tilt orientation and magnitude of eddies in storm tracks.

\section{Seasonal cycle of eddy efficiency}

\section{a. Baroclinic conversion, baroclinicity, and eddy total energy $\left(T_{e}^{\prime}\right)$}

Over the North Pacific, maximum values of $T_{e}^{\prime}$ are located near $45^{\circ} \mathrm{N}, 170^{\circ} \mathrm{W}$, which is downstream and poleward of the regions of maximum baroclinic conversion during December (Fig. 2a). The decline of $T_{e}^{\prime}$ at $500 \mathrm{hPa}$ starts after December (Fig. 2a), and $T_{e}^{\prime}$ remains suppressed, relative to the shoulder months, during January and February (Figs. 2b,c) before it increases again during March (Fig. 2d). During March, maximum values in $T_{e}^{\prime}$ are located farther upstream compared to maximum values during December and are now located near $40^{\circ} \mathrm{N}, 170^{\circ} \mathrm{E}$ over the west Pacific.

The evolution of baroclinic conversion is closely linked to $T_{e}^{\prime}$. From December to January, baroclinic conversion weakens and retreats over a smaller region over the Kuroshio Extension (black contours in Figs. 2a and $2 b$ ). Baroclinic conversion remains at a reduced level during February (Fig. 2c) and increases again during March (Fig. 2d). The maximum values in baroclinic conversion (Fig. 2) throughout the winter are located downstream and poleward of the highest values in baroclinicity (green contour in Fig. 2). High baroclinicity (green contour in Figs. 2a-d), located between $30^{\circ}$ and $40^{\circ} \mathrm{N}$, is largest during January, while baroclinic conversions during January (black contour in Fig. 2a) are lower compared to December and March.

The maximum values of baroclinic conversion and $T_{e}^{\prime}$ reduce during midwinter but also move equatorward. This equatorward migration is reflected in a dipole pattern seen in baroclinic conversion changes relative to the previous month (color shading in Fig. 2). The increase in baroclinic conversion from November to December equatorward of $40^{\circ} \mathrm{N}$ (brown shading in Fig. 2a) dominates the simultaneous decrease in conversion rates poleward of $40^{\circ} \mathrm{N}$ (blue shading in Fig. 2a). From December to January, however, the decrease in baroclinic conversion, dominates over the simultaneous increase equatorward of $40^{\circ} \mathrm{N}$ (blue shading in Fig. 2b). From January to February, the changes in baroclinic conversion rates are weak (Fig. 2c). From February to March, baroclinic conversion mitigates poleward, reintensifies in a southwestto-northeast-oriented band (brown shading in Fig. 2d) and $T_{e}^{\prime}$ acquires a new maximum near $40^{\circ} \mathrm{N}, 170^{\circ} \mathrm{E}$, while baroclinicity (green contour in Fig. 2d) has weakened compared to February. In the following section, we discuss the seasonal evolution of the eddy efficiency and compare its cycle with that of the baroclinic conversion and baroclinicity discussed above.

\section{VERTICAL CROSS SECTIONS}

The seasonal decline in ETE starts after October in the upper troposphere between 300 and $200 \mathrm{hPa}$ (red contours in Fig. 3). ETE exhibits a midwinter minimum, which affects mostly the mid- and upper troposphere, during January and February. ETE increases again in March throughout the troposphere. Baroclinicity increases during the winter season, and its maximum is reached during January between 500 and $400 \mathrm{hPa}$ south of $40^{\circ} \mathrm{N}$ (green contours in Fig. 3). Baroclinic conversion exhibits an isolated upper tropospheric maximum in October at $300 \mathrm{hPa}$ (black contours), which vanishes during November (blue shading in Fig. 3b). South of $40^{\circ} \mathrm{N}$ baroclinic conversion increases between 300 and $200 \mathrm{hPa}$ from October to November and below $400 \mathrm{hPa}$ it even increases north of $40^{\circ} \mathrm{N}$ (brown shading in Figs. $3 \mathrm{a}$ and $3 \mathrm{~b}$ ). From November to January, baroclinic conversion increases throughout the troposphere (brown shading in Figs. 3c and $3 \mathrm{~d}$ ), but only south of $40^{\circ} \mathrm{N}$. At the same time, baroclinic conversion decreases north of $40^{\circ} \mathrm{N}$, throughout the troposphere (blue shading in Figs. $3 \mathrm{c}$ and $3 \mathrm{~d}$ ), which is in agreement with the southward migration of the jet. Baroclinic conversion increases again in March between 700 and $500 \mathrm{hPa}$ north of $40^{\circ} \mathrm{N}$ (brown shading in Fig. 3f).

\section{b. Eddy efficiency $\left(E_{\mathrm{ff}}\right)$}

The seasonal cycle of $E_{\mathrm{ff}}$ exhibits a midwinter suppression, in agreement with baroclinic conversion rates, but in contrast to baroclinicity (Fig. 4). Baroclinicity increases moderately from December to January (green contours in Figs. $4 \mathrm{a}$ and $4 \mathrm{~b}$ ). The wintertime maximum in baroclinicity is found during January near $35^{\circ} \mathrm{N}, 150^{\circ} \mathrm{E}$ (Fig. 4b). From January to February (Fig. 4c) and from February to March, baroclinicity declines and retreats westward (Fig. 4d). While baroclinicity peaks during midwinter, $E_{\mathrm{ff}}$ however reduces near the northern seeding entrance of the main storm-track region (blue shading in Figs. 4a and 4b). In general, $E_{\mathrm{ff}}$ is highest downstream and poleward of the maximum values in baroclinicity and upstream and equatorward of the maximum values in $T_{e}^{\prime}$ in fairly good agreement with the baroclinic conversion (not shown). From November to December (Fig. 4a), $E_{\mathrm{ff}}$ decreases between $40^{\circ}$ and $60^{\circ} \mathrm{N}$ and $140^{\circ} \mathrm{E}$ and $180^{\circ}$ (blue shading in Fig. 4a), while it increases equatorward in a zonally confined band that extends across the North Pacific, in agreement 

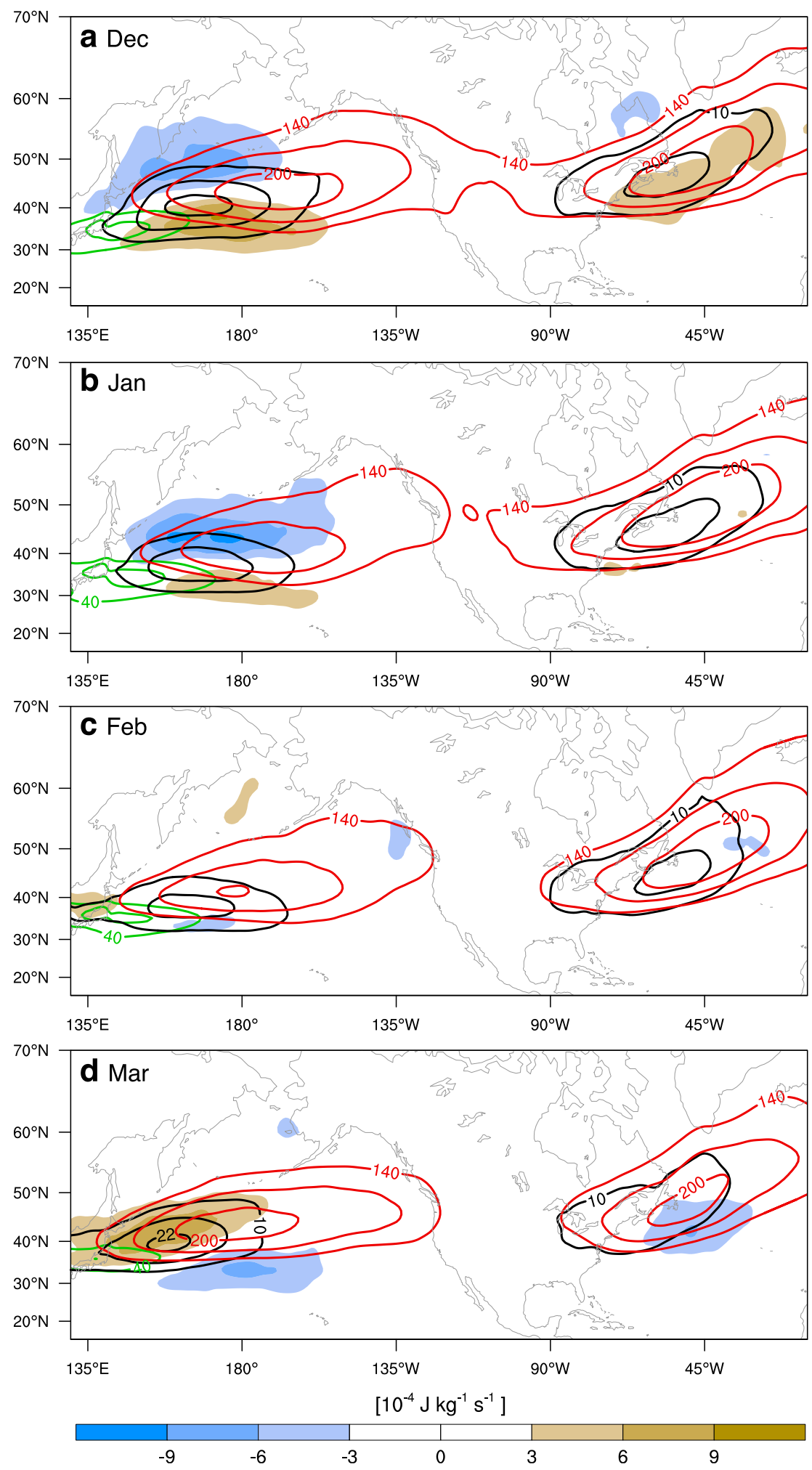

FIG. 2. Baroclinic conversion rate $\mathbf{Q}_{\mathrm{s}} \cdot \mathbf{B}_{s}$ (black contours, 10 to 28 in steps of 6; $10^{-4} \mathrm{~J} \mathrm{~kg}^{-1} \mathrm{~s}^{-1}$ ), its change relative to the corresponding previous month (color shading, -9 to 9 in steps of $3 ; 10^{-4} \mathrm{~J} \mathrm{~kg}^{-1} \mathrm{~s}^{-1}$ ), baroclinicity $\left|\mathbf{B}_{s}\right|$ (green contour; $40,45 \times 10^{-6} \mathrm{~s}^{-1}$ ), and eddy total energy $T_{e}^{\prime}$ (red contours; 140,170 , and $200 \mathrm{~J} \mathrm{~kg}^{-1}$ ) at $500 \mathrm{hPa}$ for (a) December, (b) January, (c) February, and (d) March. 

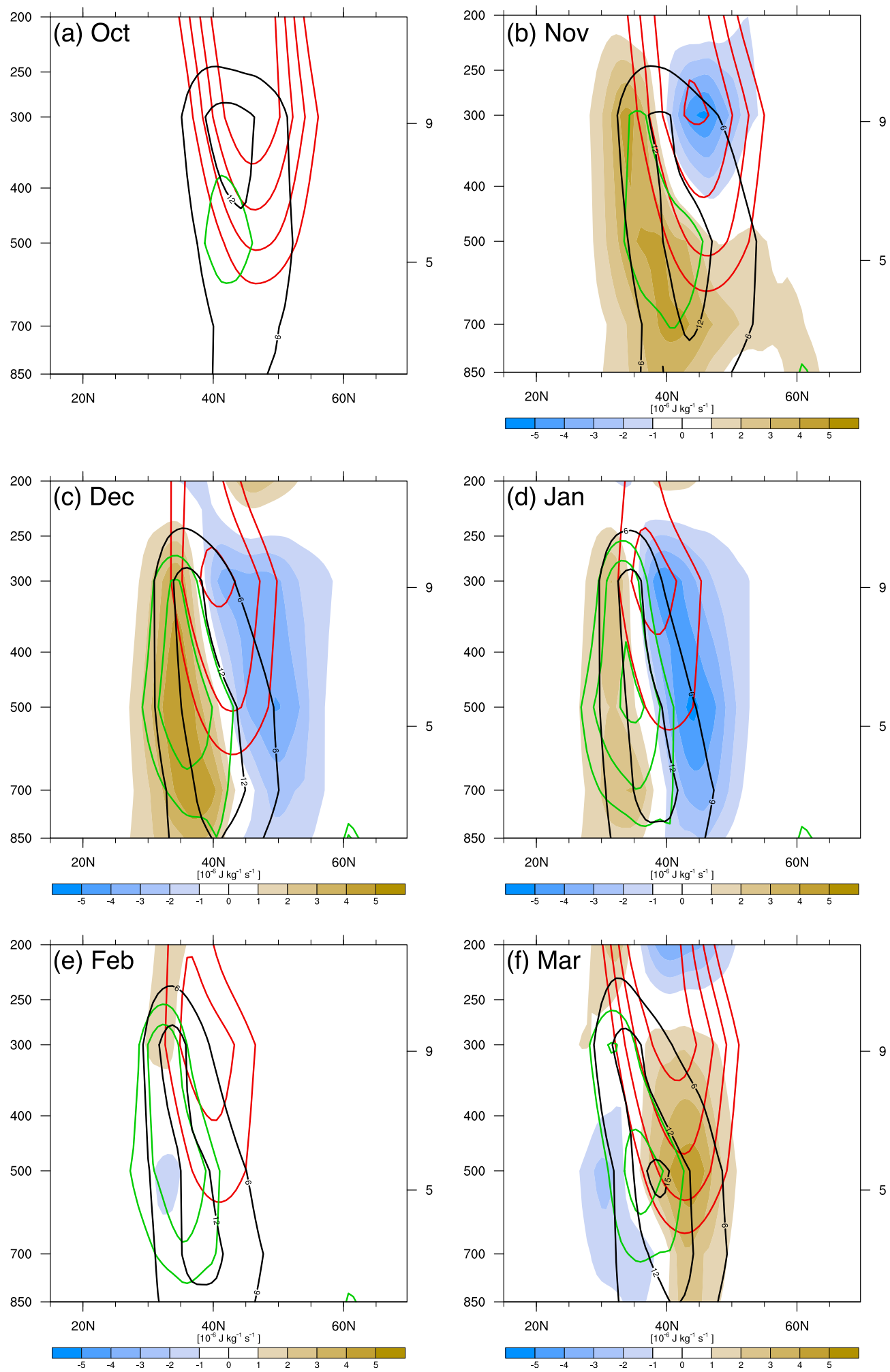

FIG. 3. Zonal-mean $\left(120^{\circ} \mathrm{E}-160^{\circ} \mathrm{W}\right)$ vertical cross sections of baroclinicity $\left|\mathbf{B}_{s}\right|$ (green contour; 30, 35, $40 \times$ $10^{-6} \mathrm{~s}^{-1}$ ), baroclinic conversion rate (black contours, 6 and $12 \times 10^{-4} \mathrm{~J} \mathrm{~kg}^{-1} \mathrm{~s}^{-1}$ ), eddy total energy $T_{e}^{\prime}($ red contours; $140,160,180$, and $200 \mathrm{~J} \mathrm{~kg}^{-1}$ ), and change in baroclinic conversion relative to the corresponding previous month (color shading; not shown for October). 

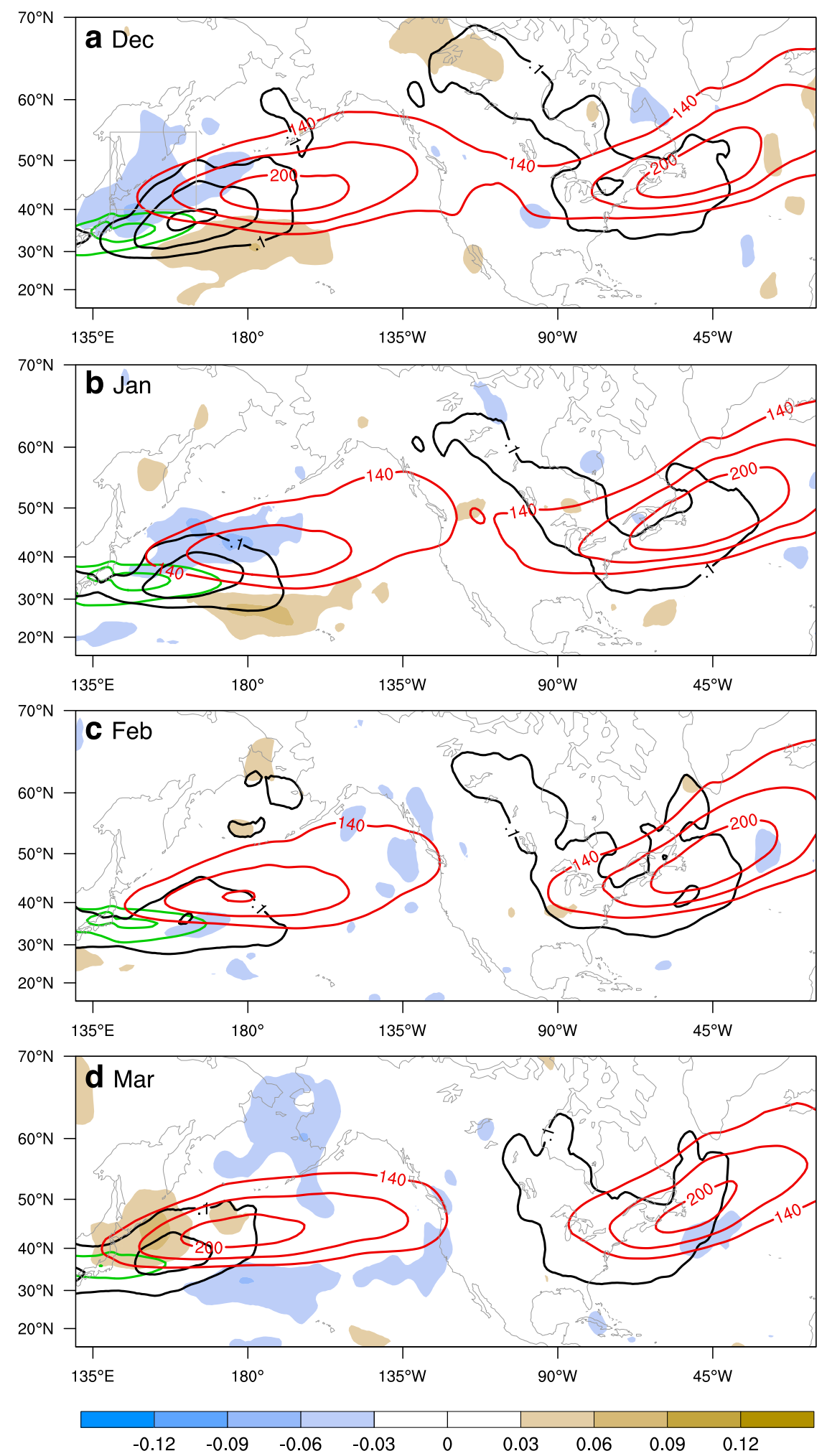

FIG. 4. Eddy efficiency $E_{\mathrm{ff}}$ (black contours; 0.1, 0.15, 0.2) and change in $E_{\mathrm{ff}}$ relative to the corresponding previous month (color shading) and eddy total energy $T_{e}^{\prime}$ (red contours; 140 , 170, and $200 \mathrm{~J} \mathrm{~kg}^{-1}$ ) at $500 \mathrm{hPa}$ for (a) December, (b) January, (c) February, and (d) March. All other fields as in Fig. 2. 
with higher baroclinic conversion during December compared to November south of $40^{\circ} \mathrm{N}$ and a corresponding reduction north of $40^{\circ} \mathrm{N}$ (brown and blue shading in Fig. 2a). $T_{e}^{\prime}$ exhibits a mild increase from November to December in agreement with an overall mild increase in baroclinic conversion (net of decrease north of $40^{\circ} \mathrm{N}$ and increase south of $40^{\circ} \mathrm{N}$ ). From December to January (Fig. 4b), $E_{\mathrm{ff}}$ continues to decrease upstream and in the center of the main storm track between $40^{\circ}$ and $55^{\circ} \mathrm{N}$ and $130^{\circ} \mathrm{E}$ and $180^{\circ}$ (blue shading in Fig. $4 b)$. Further, from December to January, $E_{\mathrm{ff}}$ decreases also between $20^{\circ}$ and $55^{\circ} \mathrm{N}$ in a region far upstream of the main storm track and even ahead of the maximum in baroclinicity (Fig. 4b). The simultaneous increase in $E_{\mathrm{ff}}$ (brown shading in Fig. 4b) during January is limited to a small region far equatorward of the main storm-track region (red contours in Fig. 4b), between $15^{\circ}$ and $35^{\circ} \mathrm{N}$ and $150^{\circ} \mathrm{E}$ and $130^{\circ} \mathrm{W}$, where $T_{e}^{\prime}$ is relatively low. The month-to-month changes in baroclinic conversion, shown in Fig. 2, thus closely follow the seasonal cycle of $E_{\mathrm{ff}}$, shown in Fig. 4, with a decrease poleward of $40^{\circ} \mathrm{N}$ in a region where eddies enter the North Pacific storm track through the northern seeding branch and a simultaneous increase equatorward of the storm track. Next, we explore in greater detail the processes that affect $E_{\mathrm{ff}}$, in particular, the eddy tilt orientation and eddy tilt magnitude.

\section{VERTICAL CROSS SECTIONS}

From October to January, the eddy efficiency increases south of $40^{\circ} \mathrm{N}$ throughout the troposphere but the increase is strongest in the mid- and lower troposphere (brown shading in Figs. 5a-d), where the eddy efficiency is highest (black contours in Fig. 5). North of $40^{\circ} \mathrm{N}$, in the region of upstream seeding to the North Pacific storm track, the eddy efficiency reduces from November to January throughout the troposphere. Eddies entering the North Pacific storm track thus become less efficient in converting the mean baroclinicity, which has a maximum slightly south of $40^{\circ} \mathrm{N}$ at $500 \mathrm{hPa}$ in January (Fig. 5d), into eddy total energy. In other words, the eddy efficiency decrease north of $40^{\circ} \mathrm{N}$ has a stronger effect than the eddy efficiency increase south of $40^{\circ} \mathrm{N}$ because the eddy total energy is stronger in the former region than in the latter region (see the collocation between the blue shadings and the red contours in Figs. 5a and 5d).

(i) Eddy tilt orientation efficiency $\left(E_{\mathrm{ff}} \nless\right)$. The eddy tilt orientation efficiency, $E_{\mathrm{ff} \nless} \equiv \cos \left(\mathbf{Q}_{s}, \mathbf{B}_{s}\right)$, exhibits a clear midwinter suppression upstream of the entrance into the main storm-track region (Fig. 6). $E_{\mathrm{ff} \nless}$ decreases (blue shading in Figs. 6a and 6c) from
November to December and further from December to January north of $40^{\circ} \mathrm{N}$, by up to $50 \%$, and increases again from February to March (brown shading in Fig. 6e). Maximum values in $E_{\mathrm{ff}} \nless$ are reduced over the Kuroshio Extension (black contours in Figs. 6a, 6c, and $6 e)$, but the largest reduction in the eddy tilt orientation efficiency occurs over a region poleward of the Kuroshio Extension, where the angle between the heat flux $\mathbf{Q}_{s}$ (black vector in Fig. 6) and the mean baroclinicity $\mathbf{B}_{s}$ (green vector in Fig. 6) increases from November to December and January. The more eastward orientation of the eddy heat flux during January suggests a poleward tilt with height of the eddy geopotential isolines propagating in this region. In addition to a more eastward orientation of the eddy heat flux a close inspection of the vector orientation also reveals a slightly more westward-oriented baroclinicity vector during January compared to December, which is another change relevant for understanding the decrease in $E_{\mathrm{ff} \nless}$. Farther equatorward, $E_{\mathrm{ff}} \nless$ increases from November to January across the North Pacific within a zonal band between $20^{\circ}$ and $40^{\circ}$ (brown shading in Figs. $6 a$ and $6 \mathrm{c}$ ). However, this increase is far away from the main storm-track region. During March, $E_{\mathrm{ff} \nless}$ increases in a broader region between $20^{\circ}$ and $60^{\circ} \mathrm{N}$ west of $180^{\circ}$, while it decreases east of $180^{\circ}$ over the exit region of the main storm track (blue shading in Fig. 6e). The evolution of $E_{\mathrm{ff} \nless}$ thus matches closely that of the total eddy efficiency $E_{\mathrm{ff}}$ (cf. Fig. 4). Thus, eddies becomes less efficient in extracting $T_{e}^{\prime}$ from $\mathbf{B}_{s}$ poleward of $40^{\circ} \mathrm{N}$, which is upstream of the main storm-track region, while they increase their efficiency equatorward of $40^{\circ} \mathrm{N}$, which is, however, far away from the main stormtrack region.

(ii) Eddy tilt magnitude efficiency $\left(E_{\mathrm{ff} \|}\right)$. The eddy tilt magnitude efficiency $E_{\mathrm{ff} \|} \equiv\left|\mathbf{Q}_{s}\right| / T_{e}^{\prime}$ increases poleward between 0.6 and 0.7 , while the associated relative monthly changes, are in general small (Figs. 6b,d,f) and, in contrast to those of the eddy tilt orientation efficiency, do not follow a seasonal cycle that parallels the midwinter suppression. $E_{\mathrm{ff} \|}$ declines from December to January north of $40^{\circ} \mathrm{N}$ while it increases equatorward (brown shading in Figs. 6b and 6d). During January there is a mild decrease near the center of maximum values in the baroclinicity magnitude. During March, the pattern suggests a poleward increase of eddy tilt magnitude with a reduction equatorward of $40^{\circ} \mathrm{N}$ (Fig. 6h) opposed to what is found for December (Fig. 6b). However, the patterns are not as clear as for the eddy tilt orientation efficiency and it appears as if the seasonal cycle is driven by the change in the eddy tilt orientation with a weak 

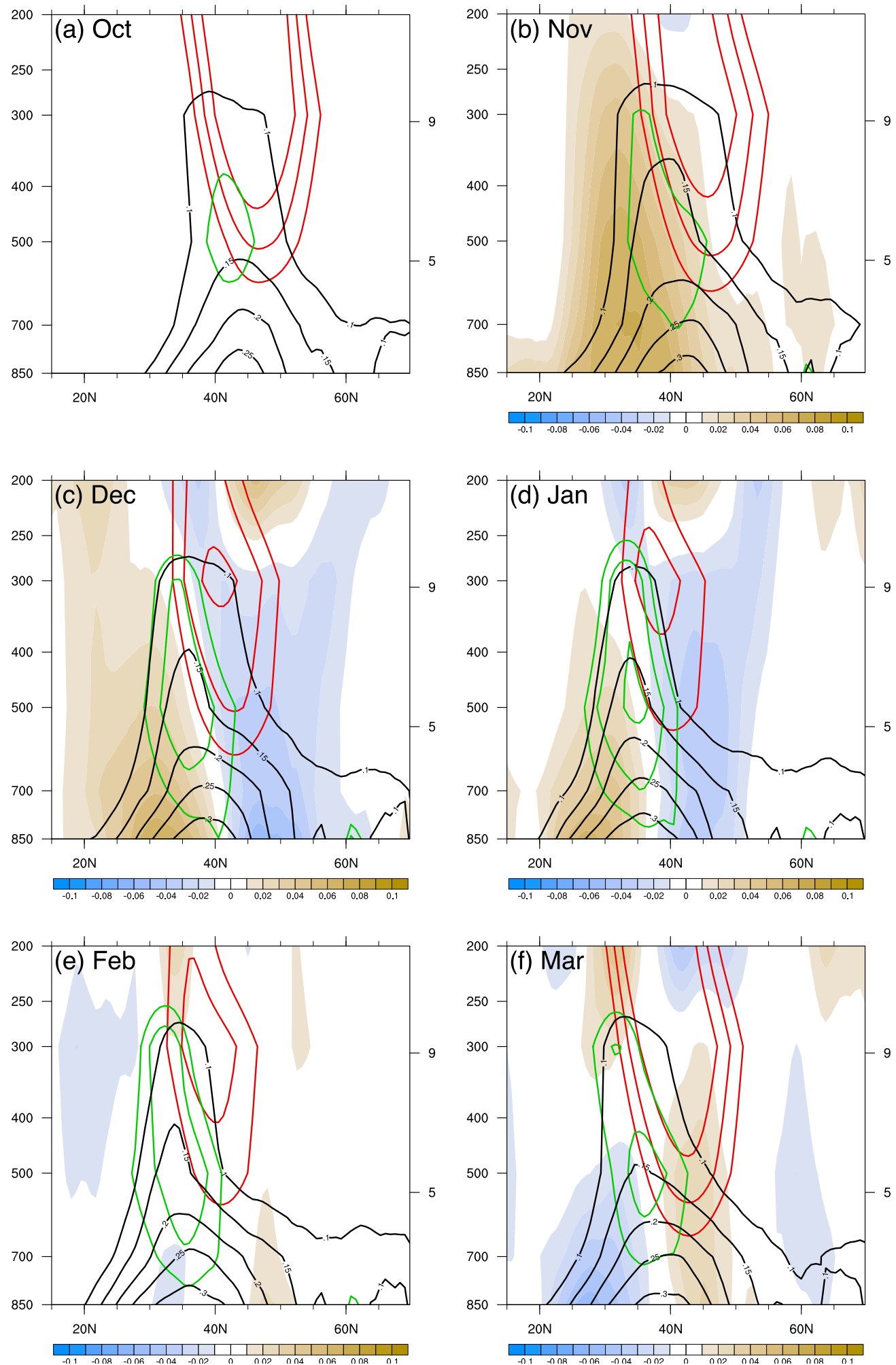

FIG. 5. Zonal-mean $\left(120^{\circ} \mathrm{E}-160^{\circ} \mathrm{W}\right)$ vertical cross sections of baroclinicity $\left|\mathbf{B}_{s}\right|$ (green contour; 30, 35, $40 \times$ $10^{-6} \mathrm{~s}^{-1}$ ), eddy total energy $T_{e}^{\prime}$ (red contours; $140,160,180$, and $200 \mathrm{~J} \mathrm{~kg}^{-1}$ ), eddy efficiency (black contours; 0.1 to 0.3 in steps of 0.05 ), and change in eddy efficiency relative to the corresponding previous month (color shading; not shown for October). 

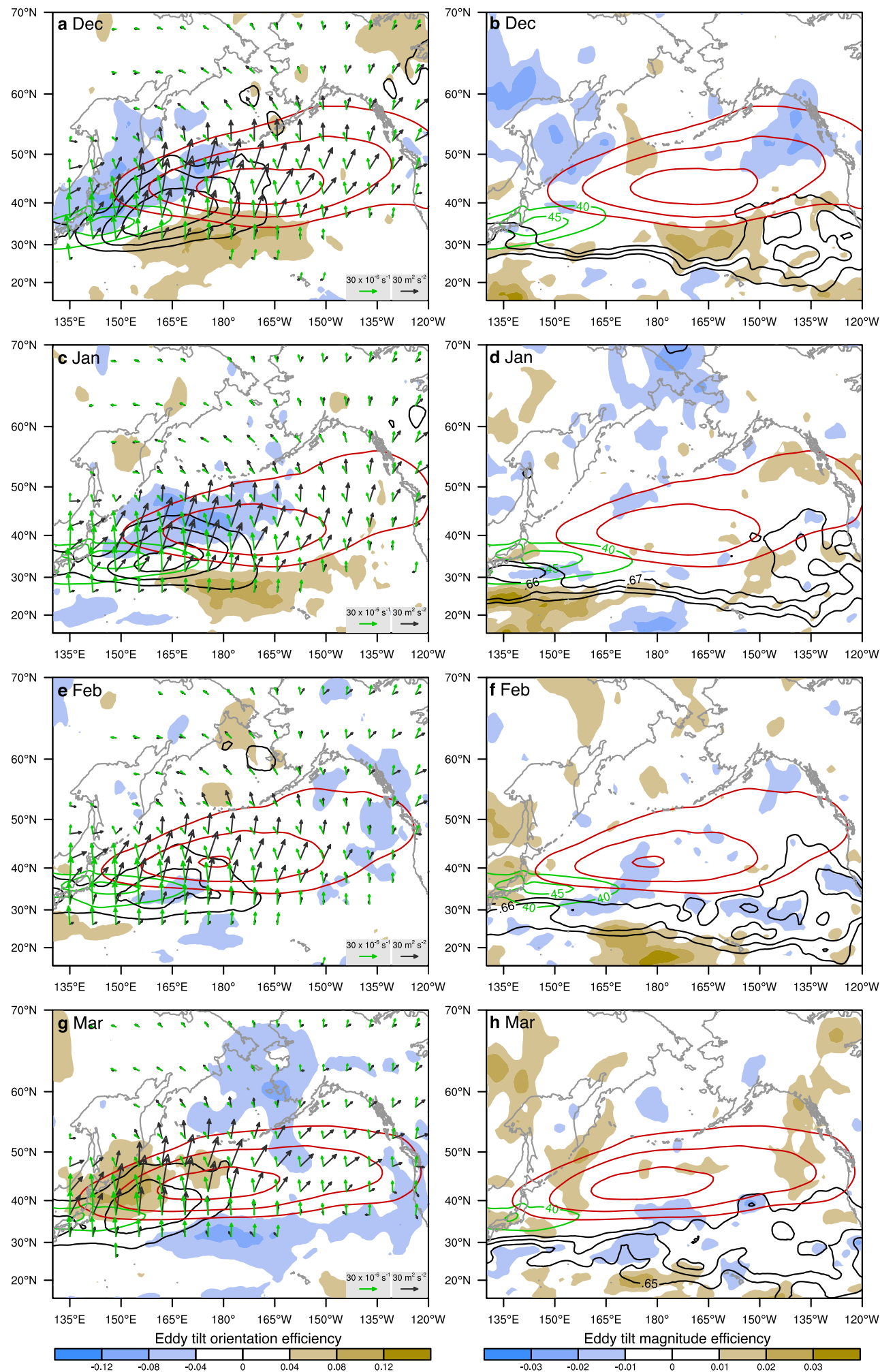

Fig. 6. (left) Eddy tilt orientation efficiency $E_{\mathrm{ff} \nless} \equiv \cos \left(\mathbf{Q}_{s}, \mathbf{B}_{s}\right)$ (black contours, 0.1-0.4 by 0.05), baroclinicity $\mathbf{B}_{s}$ (green vectors), and stability-normalized eddy heat flux $\mathbf{Q}_{s}$ vectors (black vectors). (right) Eddy tilt magnitude efficiency $E_{\mathrm{ff} \|}=\mathbf{Q}_{s} / T_{e}^{\prime}$ (black contours 0.66, 0.67, and 0.68) for (a),(b) December, (c),(d) January, (e),(f) February, and (g),(h) March. Also shown is the efficiency change relative to the corresponding previous month (color shading). Eddy total energy $T_{e}^{\prime}$ (red contours; 140, 170, and $200 \mathrm{~J} \mathrm{~kg}^{-1}$ ) and baroclinicity $\left|\mathbf{B}_{s}\right|$ (green contours) as in Figs. 2 and 4. 

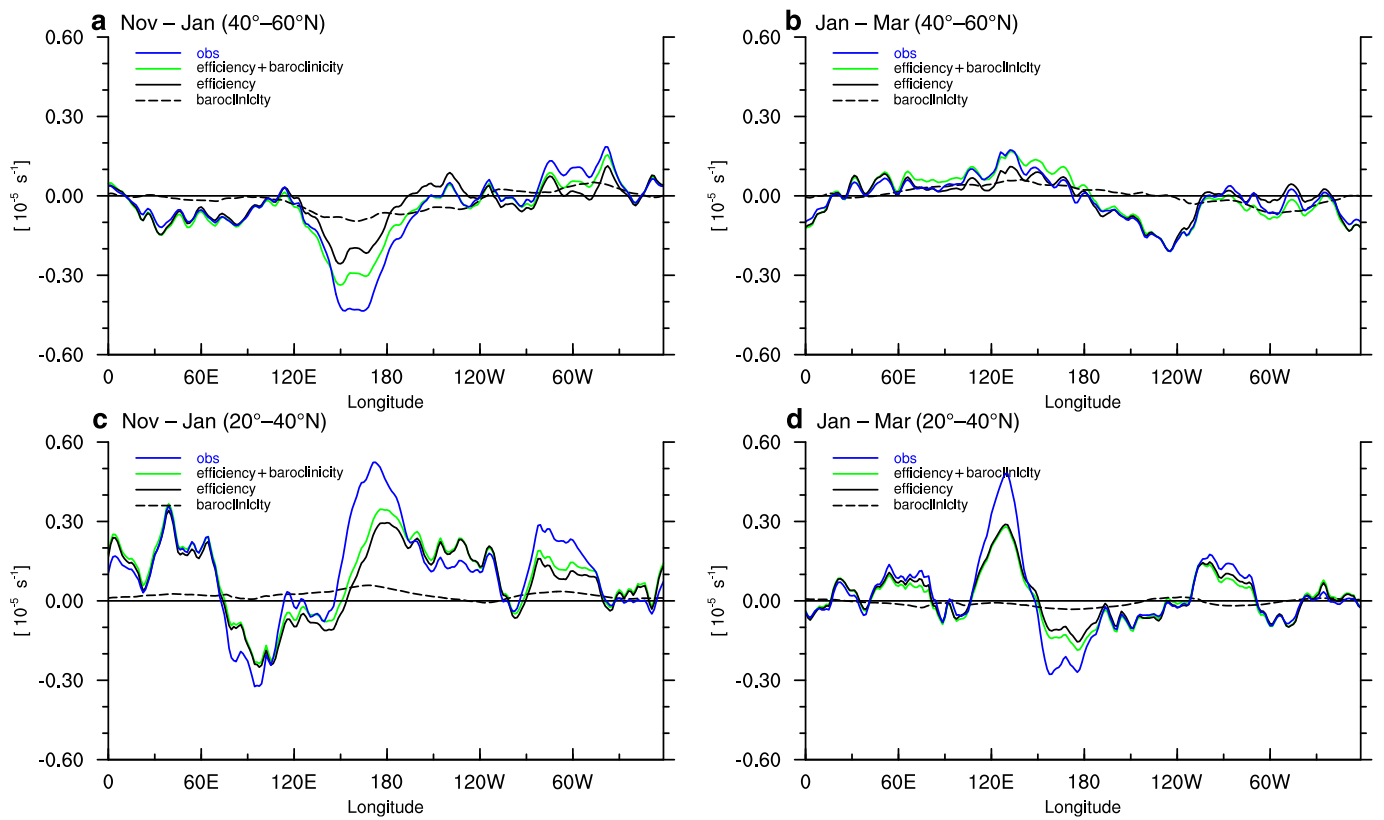

FIG. 7. Baroclinic growth rate budget [cf. Eq. (11)] for growth rate change between (left) January and November and (right) March and January averaged between (a),(b) $40^{\circ}-60^{\circ}$ and (c),(d) $20^{\circ}-40^{\circ}$, which are the two latitude bands where the largest changes in baroclinic conversion are observed (cf. Fig. 2b). Shown are changes in baroclinic growth rate due to the change in baroclinicity (black dashed) and eddy efficiency (black solid). Also shown are the sum of both (green contour) and the observed change (blue contours).

change observable in the eddy tilt magnitude. We will discuss this again in the section based on the Lagrangian cyclone tracking.

\section{c. Baroclinic conversion budget}

Further insights into the relative contributions from baroclinicity $\mathbf{B}_{s}$ and eddy efficiency $E_{\mathrm{ff}}$ changes to the evolution of baroclinic conversion can be gained by linearizing Eq. (5),

$$
\begin{aligned}
\left\langle T_{e}^{\prime}\left|\mathbf{B}_{s}\right| E_{\mathrm{ff}}\right\rangle_{\mathrm{Jan}}= & \left\langle T_{e}^{\prime}\left|\mathbf{B}_{s}\right|\right\rangle_{\mathrm{Jan}}\left\langle E_{\mathrm{ff}}\right\rangle_{\mathrm{C}} \\
& +\left\langle T_{e}^{\prime} E_{\mathrm{ff}}\right\rangle_{\mathrm{Jan}}\left\langle\left|\mathbf{B}_{s}\right|\right\rangle_{\mathrm{C}}+R_{\mathrm{Jan}},
\end{aligned}
$$

where $\langle\cdot\rangle_{\mathrm{Jan}}$ denotes a latitudinal average for January, $\langle\cdot\rangle_{c}$ a constant value computed by averaging first across a latitude band between $20^{\circ}$ and $60^{\circ} \mathrm{N}$ at each longitude and then from November to March, and the residual $R_{\mathrm{Jan}}=\left\langle T_{e}^{\prime}\left(\left|\mathbf{B}_{s}\right| E_{\mathrm{ff}}-\left\langle\left|\mathbf{B}_{s}\right|\right\rangle_{c} E_{\mathrm{ff}}-\left\langle E_{\mathrm{ff}}\right\rangle_{c}\left|\mathbf{B}_{s}\right|\right)\right\rangle_{\mathrm{Jan}}$. All averages are weighted by the cosine of latitude. The budget for a change in baroclinic conversion due to changes in $\mathbf{B}_{s}$ and $E_{\mathrm{ff}}$ between two consecutive months is

$$
\begin{aligned}
\left\langle T_{e}^{\prime}\left|\mathbf{B}_{s}\right| E_{\mathrm{ff}}\right\rangle_{\mathrm{Jan}}-\left\langle T_{e}^{\prime}\left|\mathbf{B}_{s}\right| E_{\mathrm{ff}}\right\rangle_{\mathrm{Dec}} \\
=\left\langle E_{\mathrm{ff}}\right\rangle_{\mathrm{C}}\left[\left\langle T_{e}^{\prime}\left|\mathbf{B}_{s}\right|\right\rangle_{\mathrm{Jan}}-\left\langle T_{e}^{\prime}\left|\mathbf{B}_{s}\right|\right\rangle_{\mathrm{Dec}}\right] \\
\quad+\left\langle\left|\mathbf{B}_{s}\right|\right\rangle_{\mathrm{C}}\left[\left\langle T_{e}^{\prime} E_{\mathrm{ff}}\right\rangle_{\mathrm{Jan}}-\left\langle T_{e}^{\prime} E_{\mathrm{ff}}\right\rangle_{\mathrm{Dec}}\right]+R_{\mathrm{Dec}}-R_{\mathrm{Jan}},
\end{aligned}
$$

where the first term on the right-hand side denotes changes in baroclinic conversion due to changes in baroclinicity and the second term on the right-hand side changes in baroclinic conversion due to changes in eddy efficiency. Finally, we note that all terms in Eq. (11) are normalized by the corresponding monthly mean $\left\langle T_{e}^{\prime}\right\rangle$ to obtain actual growth rates.

From November to January and poleward of $40^{\circ} \mathrm{N}$, the reduction in eddy efficiency over the central $\mathrm{Pa}-$ cific (Fig. 7a) brings strong similarities with the total baroclinic growth rate (black solid contour in Fig. 7a between $120^{\circ} \mathrm{E}$ and $180^{\circ}$ ), but the residual is nonnegligible (difference between blue and green contours in Fig. 7a). The reduction in baroclinic conversion due to reduced baroclinicity (dashed contour in Fig. 7a) is connected to the equatorward migration of the jet. However, the contribution to the reduction of the growth rate by reduced eddy efficiency dominates over the contribution due to reduced baroclinicity poleward of $40^{\circ} \mathrm{N}$. Equatorward of $40^{\circ} \mathrm{N}$ (Fig. 7c), baroclinic growth rates increase over the main Pacific storm-track region $\left(130^{\circ} \mathrm{E}-150^{\circ} \mathrm{W}\right)$. This increase is mostly driven by an increase in eddy efficiency (Fig. 7c); however, the residual term is again nonnegligible. The fact that the change in baroclinic conversion due to baroclinicity is positive south of $40^{\circ} \mathrm{N}$ reflects the equatorward migration of the jet 

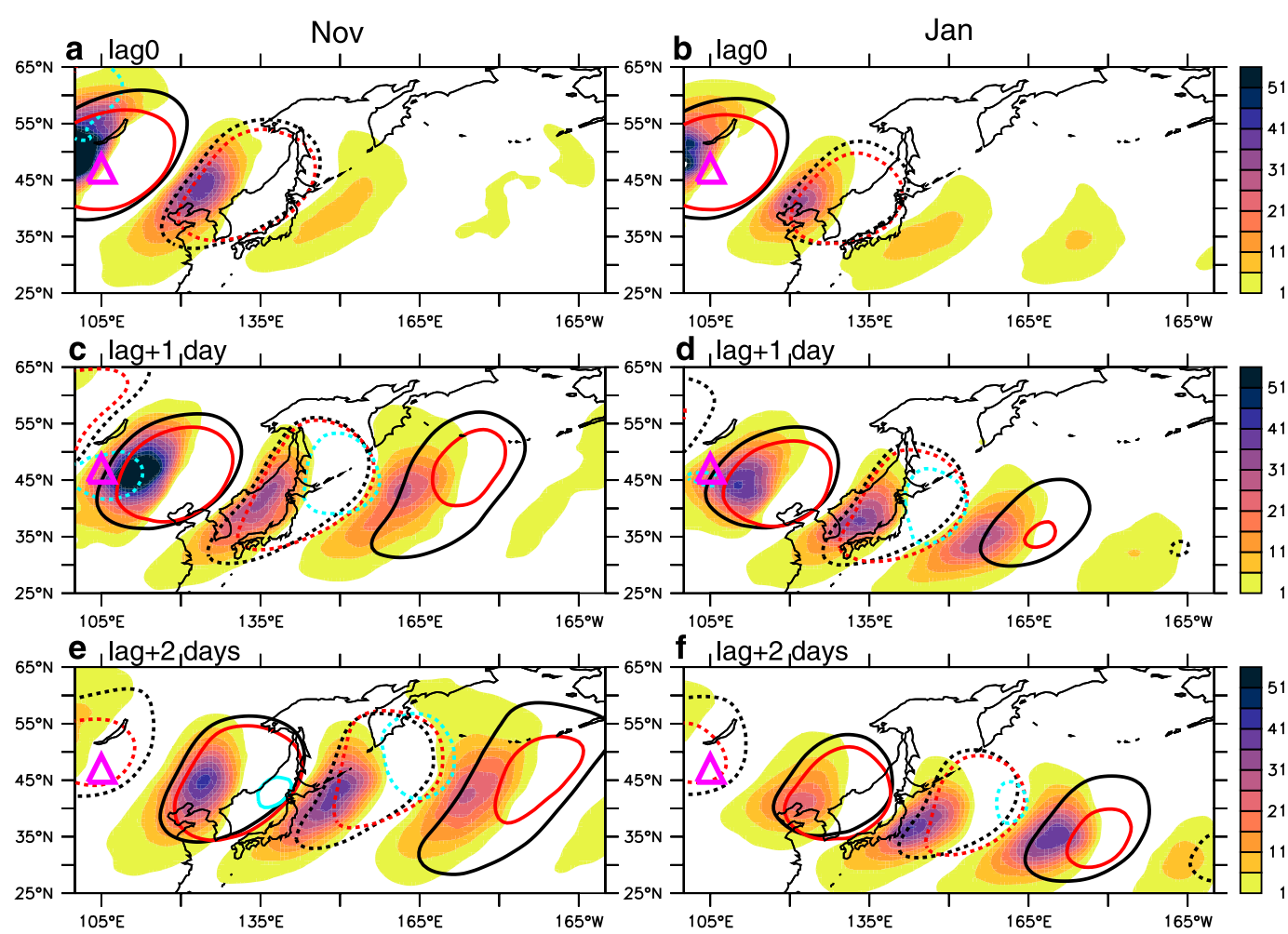

FIG. 8. One-point regression based on 300-hPa high-pass geopotential height at $47^{\circ} \mathrm{N}, 105^{\circ} \mathrm{E}$ for (left) November and (right) January and for lags of (a),(b) 0 day, (c),(d) +1 day and (e),(f) +2 days. The black, red, and blue contours correspond to the $10 \mathrm{-m}$ regressed high-pass geopotential height at 300,500 , and $800 \mathrm{hPa}$, respectively (dashed for negative and solid for positive). The baroclinic conversion is shown in shadings (units: $10^{-5} \mathrm{~m}^{2} \mathrm{~s}^{-3}$ ). The regressed high-pass wind and temperature fields are used to compute the eddy heat fluxes and the climatology of the individual months to compute the baroclinicity. The purple triangle corresponds to the reference point.

stream and an overall increase in baroclinicity from November to January.

From January to March (Fig. 7b), baroclinic growth rates increase over wide parts of the western Pacific storm track north of $40^{\circ} \mathrm{N}$, and this is due to a combination of increased baroclinicity, which migrates poleward in tandem with the jet stream, and an increase in eddy efficiency. In the eastern Pacific around $150^{\circ} \mathrm{W}$ baroclinic conversion decreases at the end of the storm track (Fig. 7b; see also Fig. 4d). Equatorward of $40^{\circ} \mathrm{N}$, the budget indicates an increase in baroclinic growth rates between $110^{\circ}$ and $150^{\circ}$ and a decrease downstream between $150^{\circ}$ and $190^{\circ}$. This pattern is a result of an increase in baroclinic conversion that is stretching from the southwest to the northeast across the western Pacific (cf. brown shading in Fig. 2d).

In general, and in agreement with the previous analysis, most changes in baroclinic growth rates during midwinter are the result of changes in eddy efficiency. However, changes in eddy efficiency have a larger impact in regions where $T_{e}^{\prime}$ is also large, which is the case north of $40^{\circ} \mathrm{N}$. The decrease in eddy efficiency north of $40^{\circ} \mathrm{N}$ has therefore a larger impact on eddy growth than the increase in eddy efficiency equatorward of $40^{\circ} \mathrm{N}$.

\section{Evolution and structure of baroclinic waves as inferred from regression maps}

In the previous sections, we identified a reduction in baroclinic eddy growth upstream of the main stormtrack region, and we traced this reduction back to a reduction in the eddy efficiency. More precisely, we find a wintertime evolution in the eddy tilt orientation efficiency, $E_{\mathrm{ff} \nless}$, that matches a suppression. The vertical tilt of the growing eddies appears to drive a more eastwardoriented eddy heat flux, which suggest a more poleward orientation of the vertical tilt of the eddy geopotential isolines in this region. In this section, we use regression maps to get a better insight into the structure of baroclinic waves when they enter the Pacific storm-track from the northern branch of upstream seeding (Chang 2005) and into their evolution over the North Pacific.

Figure 8 shows time-lag regression maps for two distinct months, November and January, based on the 

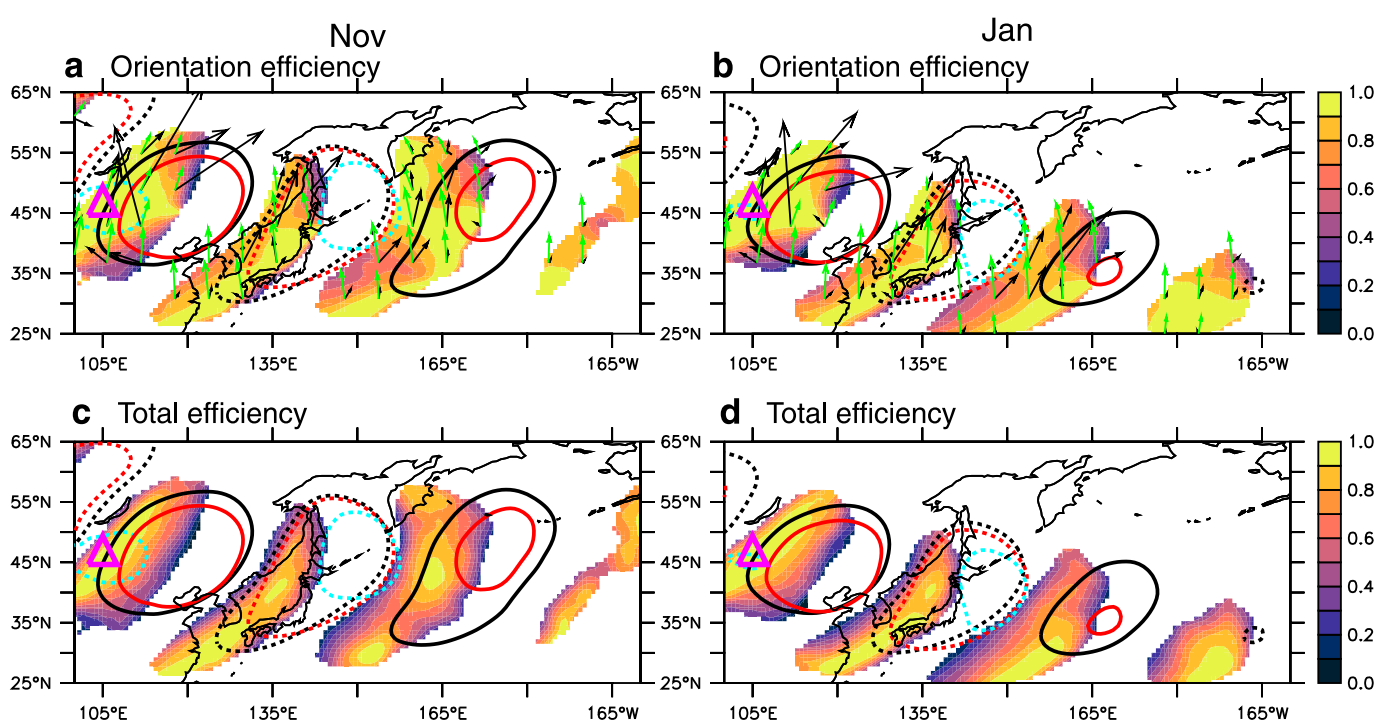

FIG. 9. As in Figs. $8 \mathrm{c}$ and $8 \mathrm{~d}$, but the color shadings represent the eddy tilt orientation efficiency $E_{\mathrm{ff}} \nless$ in (a),(b) and the total eddy efficiency $E_{\mathrm{ff}}$ in (c),(d) in regions where the baroclinic conversion is greater than $10^{-3} \mathrm{~m}^{-2} \mathrm{~s}^{-3}$. In (a),(b) the green and black arrows correspond to the baroclinicity vectors $\mathbf{B}_{s}$ and stability-normalized eddy heat flux $\mathbf{Q}_{s}$ vectors respectively.

$300-\mathrm{hPa}$ high-pass geopotential height at $47^{\circ} \mathrm{N}, 105^{\circ} \mathrm{E}$, which is within the northern branch of upstream seeding. The reference point is the same as in Fig. 3 of Nakamura and Sampe (2002). At lag 0 day, the regressed geopotential has slightly stronger amplitude in November but not much difference between the two months is noticeable in the structure of the wave packet itself. However, at lags +1 and +2 days, when the wave has entered the North Pacific the propagation and the structure of the wave packets starts to differ between the two months, in particular at lag 2 day (Figs. 8e,f). In November, the propagation is much more zonal, and the eddies are more meridionally stretched compared to January. For the latter month, the propagation is more equatorward and toward the more subtropical jet, this is because the maximum baroclinicity is located farther south during January as it migrates in tandem with the jet equatorward (Fig. 2) and the baroclinic interaction associated with developing eddies entering the Pacific through the northern branch of seeding will necessarily occur farther equatorward. The peak amplitudes of the baroclinic conversion inferred from the regressed fields are almost the same for the two months in the western Pacific but regions spanned by high values of the baroclinic conversion cover a larger area in November than January. In particular, the two regions of baroclinic conversion (up- and downstream of $135^{\circ} \mathrm{E}$ ) at lag +2 days are noticeably weaker during January compared to November, which agrees with the region of reduced baroclinic conversion during January seen in the monthly climatology (blue shading in Fig. 2b). Closer to the surface, at $800 \mathrm{hPa}$, the minimum of the regressed geopotential moves poleward from lags +1 to +2 days in November (Figs. 8 c,e) while it moves more zonally and even slightly equatorward in January (Figs. 8d,f).

A major difference in the eddy tilt orientation efficiency between the two months appears south of the Kamchatka peninsula, at the entrance region into the main storm track, at lag +1 day (see the area between $150^{\circ} \mathrm{E}$ and $165^{\circ}$ and between $35^{\circ} \mathrm{N}$ and $55^{\circ}$ in Figs. $9 \mathrm{a}$ and $9 \mathrm{~b})$. November is marked by a much higher orientation efficiency due to a better alignment between the eddy heat fluxes and the baroclinicity than in January. In the former month, tubes of constant eddy geopotential height mainly tilt westward with height (consistent with a northward eddy heat flux), whereas in the latter month the tilt with height is more northwestward and the eddy heat fluxes point northeastward (black vectors in Figs. 9a and 9b). This difference is mainly responsible for the difference in the total eddy efficiency in that storm-track entrance region (Figs. 9c,d) and well illustrates the differences seen in climatologies of eddy efficiency shown in Figs. 4 and 6. To conclude, the regression maps show that the more equatorward propagation of the wave packet in January is closely related to a more northwestward tilt with height of the eddy geopotential isolines, which makes the eddies less 


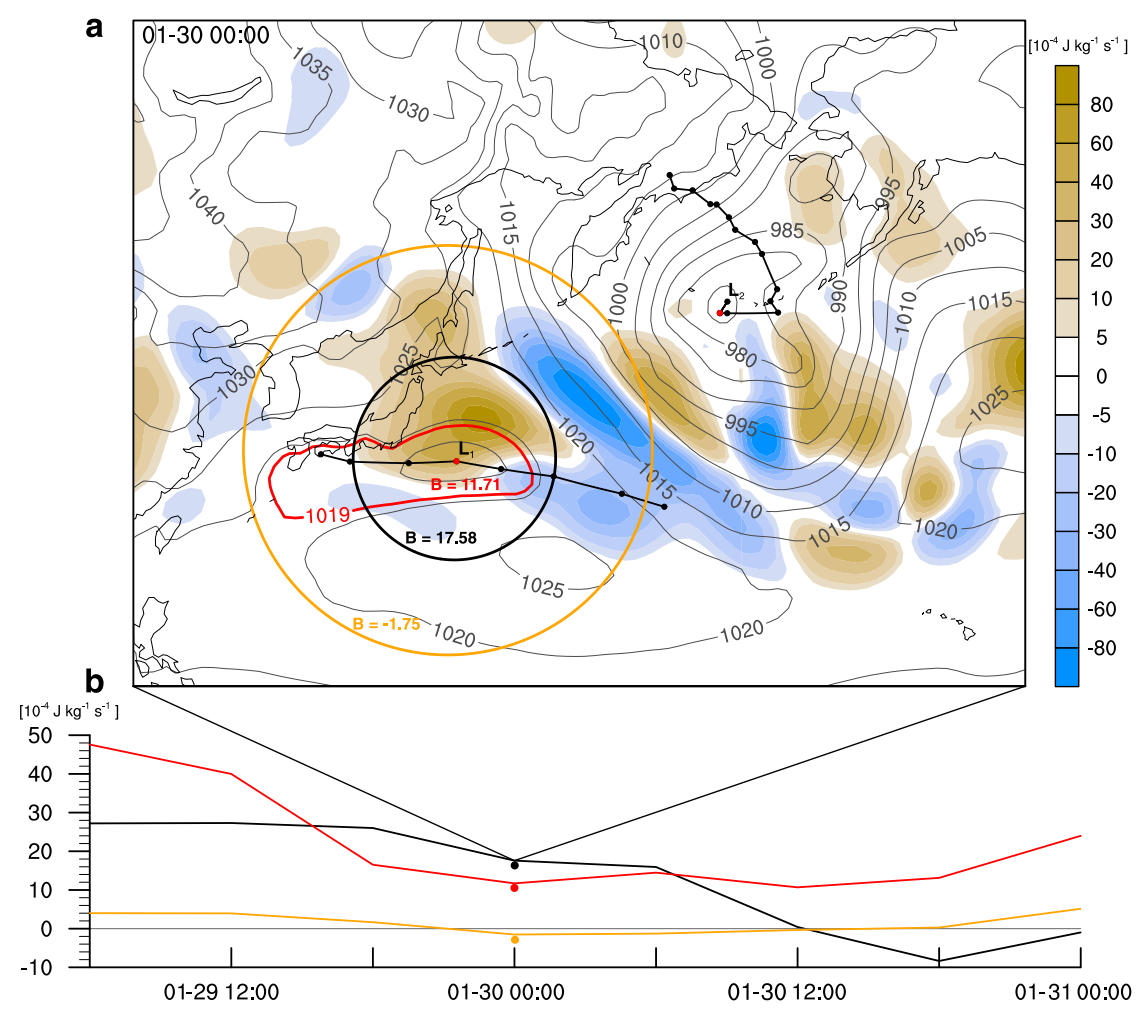

FIG. 10. (top) Tracks of two surface cyclones (labeled $\mathrm{L}_{1}$ and $\mathrm{L}_{2}$ ) with their positions at 0000 UTC 30 Jan 2016 (red points). Also shown are two circles with a radius of 1000-km (black) and 2000-km (yellow) centered on the core of the westernmost cyclone $\left(\mathrm{L}_{1}\right)$; the outermost sea level pressure contour (red; $1019 \mathrm{hPa}$ ) used by the cyclone tracking; baroclinic conversion rates at $500 \mathrm{hPa}$ (color; $10^{-4} \mathrm{~J} \mathrm{~kg} \mathrm{~s}^{-1}$ ), and surface isobars (black contours; steps of $5 \mathrm{hPa})$. Additional numbers indicate area-averaged baroclinic conversion rates $\left(10^{-4} \mathrm{~J} \mathrm{~kg} \mathrm{~s}^{-1}\right)$ for the areas encompassed by the two circles and the outermost contour. (bottom) Temporal evolution of area-averaged baroclinic conversion rates for cyclone $\mathrm{L}_{1}$.

efficient in extracting energy from the background baroclinicity than in November.

\section{Evolution and structure of baroclinic waves as inferred from feature-based tracking of surface cyclones}

Regression maps are commonly used tools to analyze storm-track dynamics but they only provide indirect information on the developing cyclones. A more direct way to get insight into the developing cyclones requires the use of a feature-based tracking of surface cyclones. In the present section, we more deeply study the vertical tilt of eddies and their baroclinic conversion for cyclones that propagate through the region of reduced eddy efficiency (blue shading in Fig. 4b) and where the regression maps suggest the largest difference in the structure of the baroclinic waves (Fig. 8 at lag +2 days). We start with an example of how we connect the tracks of surface cyclones to baroclinic conversion rates and integrated baroclinic conversion per life cycles.

On 30 January 2016, two cyclones are located over the Pacific (labeled $\mathrm{L}_{1}$ and $\mathrm{L}_{2}$ in Fig. 10a). Along their tracks, every 6-h time step is labeled by a black dot, where the red dot indicates the current time step. The tracks follow the minimum SLP inside the outermost closed SLP contour (red contour in Fig. 10a). Baroclinic conversion rates are area-averaged at $500 \mathrm{hPa}$ at every time step within a circle with a $1000-\mathrm{km}$ radius (black in Fig. 10a), a circle with a $2000-\mathrm{km}$ radius (yellow in Fig. 10a), and within the area encompassed by the outermost closed SLP contour (red contour in Fig. 10a). The temporal evolution of the three different areaaveraged baroclinic conversion rates (Fig. 10b) indicates that baroclinic conversion has a maximum during the initial 24-h period of $\mathrm{L}_{1}$. Baroclinic growth decreases after the initial growth, the decay starts at 1200 UTC 30 January and the decay weakens during the final 12-h period (Fig. 10b). The baroclinic conversion 
averaged within a circle with a $1000-\mathrm{km}$ radius is larger, relative to those with a $2000-\mathrm{km}$ radius, because the baroclinic sink downstream is outside the circle. The SLP-averaging approach is, in general, also affected by seasonal changes in cyclone areas. For the following climatological part of our analysis, we use all three averaging methods.

The area-averaged baroclinic conversion rates from each cyclone life cycle are used to obtain a mean baroclinic conversion rate for every life cycle. The mean conversion rate for every life cycle is then used to obtain monthly mean values. For the presented example (Fig. 10), the mean conversion rates for the life cycle are $13.1 \times 10^{-4} \mathrm{~J} \mathrm{~kg}^{-1} \mathrm{~s}^{-1}$ for the $1000-\mathrm{km}$ radius, $1.5 \times$ $10^{-4} \mathrm{~J} \mathrm{~kg}^{-1} \mathrm{~s}^{-1}$ for the $2000-\mathrm{km}$ radius, and $22.3 \times$ $10^{-4} \mathrm{~J} \mathrm{~kg}^{-4} \mathrm{~s}^{-1}$ for the SLP-contour approach. The integrated baroclinic conversion during the cyclone life cycle is computed to provide a net baroclinic conversion per cyclone life cycle. For the presented example, this is $2.310^{2} \mathrm{~J} \mathrm{~kg}^{-1}$ (1000-km), $3.910^{2} \mathrm{~J} \mathrm{~kg}^{-1}$ (SLP contour), and $0.2610^{2} \mathrm{~J} \mathrm{~kg}^{-1}$ (2000-km).

\section{a. Mean integrated baroclinic conversion and mean conversion rates for surface cyclone life cycles}

Consideration is first given to all cyclone life cycles over the Pacific where the reduction in eddy efficiency is most pronounced $\left(40^{\circ}-60^{\circ} \mathrm{N}, 140^{\circ}-160^{\circ} \mathrm{E}\right)$. Based on the tracking of area-averaged baroclinic conversion, we quantify the integrated baroclinic conversion per cyclone life cycle and months (Table 1). Life cycles that exist in two months are grouped as one into the month where the cyclone life cycle is longer. For the $1000-\mathrm{km}$ radius and for the SLP-contour approach, the mean integrated baroclinic conversion increases from October to December, reduces during January and increases again until March (Table 1). For the $2000-\mathrm{km}$ radius, the maximum of the integrated baroclinic conversion is found during November/December, and the reintensification during March is weaker than the other averaging procedures. This suggests that the suppression is related to processes near the cyclone center and that possibly, the monthly variations in cyclone size affect the result. Monthly changes in integrated baroclinic conversion are a function of the cyclone lifetime and reduction in the integrated conversion thus results from a reduction in the eddy lifetime in combination with a reduced mean growth rate. In general, both the averaged instantaneous baroclinic conversion rates and integrated baroclinic conversion per cyclone life cycle exhibit a midwinter suppression (Table 1). These findings are in agreement with the results of Schemm and Schneider (2018), who find a reduced EKE per cyclone life cycle during midwinter.
TABLE 1. Mean integrated baroclinic conversion $\left(10^{2} \mathrm{~J} \mathrm{~kg}^{-1}\right)$ and mean instantaneous baroclinic conversion rate at $500 \mathrm{hPa}$ (in bracket; $10^{-4} \mathrm{~J} \mathrm{~kg}^{-1} \mathrm{~s}^{-1}$ ) per life cycle for cyclones propagating through the west Pacific $\left(40^{\circ}-55^{\circ} \mathrm{N}, 140^{\circ}-165^{\circ} \mathrm{E}\right)$ for three different cyclone areas. See text for method details.

\begin{tabular}{llcl}
\hline \hline & $1000-\mathrm{km}$ & SLP contour & $2000-\mathrm{km}$ \\
\hline Oct & $2.8[7.2]$ & $3.2[8.4]$ & $1.7[4.8]$ \\
Nov & $3.3[9.3]$ & $4.2[12.2]$ & $2.1[6.5]$ \\
Dec & $3.5[10.2]$ & $4.8[14.1]$ & $2.1[6.5]$ \\
Jan & $2.6[7.4]$ & $3.5[10.1]$ & $1.7[5.4]$ \\
Feb & $3.2[9.0]$ & $3.9[11.2]$ & $1.9[5.8]$ \\
Mar & $3.9[10.5]$ & $4.4[11.6]$ & $2.2[6.4]$ \\
Apr & $3.2[9.2]$ & $3.4[9.7]$ & $1.9[5.7]$ \\
\hline
\end{tabular}

\section{b. Temporal evolution of baroclinic conversion rates during cyclone life cycles}

Next, the temporal evolution of baroclinic conversion rates during cyclone life cycles is compared between different months (Fig. 11). We focus on the period between cyclogenesis and day 6 of the life cycle. The bottom axis in Fig. 11 indicates the fraction of surface cyclones that are still detected after the indicated time period. In each panel, the mean baroclinic conversion rates, area-averaged using a $1000-\mathrm{km}$ radius, of all life cycles in one month are compared against January (solid contour in Fig. 11) and the standard deviation across all life cycles is indicated by the gray background shading.

During November, baroclinic conversion rates during the initial $48 \mathrm{~h}$ (dashed black contour in Fig. 11a), which is the period of maximum growth, are higher than the conversion rates during January (solid black contour in Fig. 11a) and fairly similar at day 4. During December (Fig. 11b), baroclinic conversion is clearly larger than that in January, from cyclogenesis until day 3 of the life cycle. For February (Fig. 12c), the evolution of baroclinic conversion is fairly comparable to that of the difference between November and January. During March (Fig. 12d). Overall, baroclinic conversion rates appear to be reduced in January, in particular during the main intensification, which lasts until approximately day 3 of an average life cycle. Note that after three days, the number of identified life cycles has approximately halved.

\section{c. Cyclone-centered composites}

The goal of this section is to better understand changes in vertical eddy structure associated with reduced eddy efficiency. The region that is affected by the strongest midwinter reduction in eddy efficiency, and by the corresponding recovery in March, is located slightly upstream of the main storm track. In the following, consideration is therefore given to all surface cyclone life cycles that propagate through this target region 

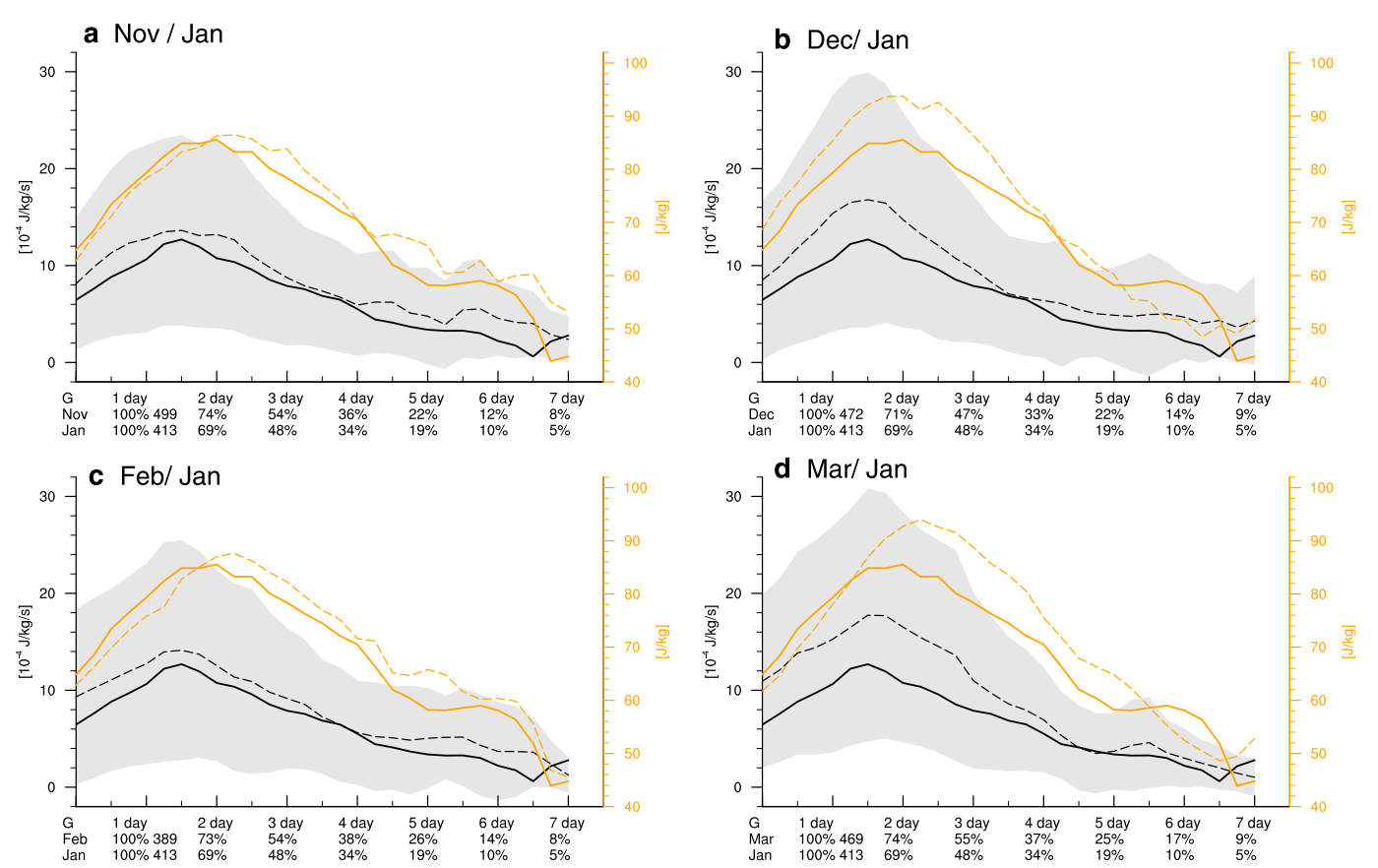

FIG. 11. Baroclinic conversion rate into eddy total energy (black contours; $10^{-4} \mathrm{~J} \mathrm{~kg}^{-1} \mathrm{~s}^{-1}$ ) and eddy kinetic energy (orange contours; $\mathrm{J} \mathrm{kg}^{-1}$ ) averaged over a 1000-km radius around the surface cyclone center during life cycles for January (solid; shown in all panels as a reference) compared with (a) November, (b) December, (c) February, and (d) March (dashed). Gray shading indicates the standard deviation of baroclinic conversion rates computed across all tracked life cycles. The bottom axis shows the percentage of life cycles that still exist after the indicated time period (note that the feature-based identification scheme considers only life cycles that exist for at least $24 \mathrm{~h}$ ) and the number of life cycles at day one. Only life cycle that propagate for one time step through the region of strong eddy efficiency reduction in December and increase in March $\left(40^{\circ}-55^{\circ} \mathrm{N}, 140^{\circ}-165^{\circ} \mathrm{E}\right)$ are considered (see thin gray box Fig. 4a).

between $40^{\circ}$ and $55^{\circ} \mathrm{N}$ and $140^{\circ}$ and $165^{\circ} \mathrm{E}$ (gray thin box in Fig. 4a). We acknowledge the fact that the stages of the cyclone life cycles in this target region may differ between the different months, but because we want to understand the reduction in eddy efficiency seen in the monthly mean climatology, we must analyze the cyclones in this region "as they are" and independent of their life cycle stage. We therefore do not center the cyclone composites shown in Figs. 12 and 13 in time on, for example, maximum intensity, but on the time when the cyclone propagates through the target region. All composites are rotated into the propagation direction of the surface cyclone track, which reduces the variability in the composite sample. On average, the angle of rotation, which is needed to rotate the northeastwardoriented cyclone tracks into the west-east direction, is $25^{\circ}$ clockwise during November, decreases toward $20^{\circ}$ during January, and increases again to approximately $25^{\circ}$ during March (the exact numbers are given in the caption of Fig. 13 and the now rotated geographical coordinate system is shown in every composite in Figs. 13 and 14). This month-to-month change in the rotation angle suggests that cyclones propagate in this target region is stronger poleward during December and March, relative to January, and less poleward/more equatorward during January, which is in agreement with the regression maps. In the following, we explore changes in the vertical eddy structure and associated changes in eddy efficiency.

First, consideration is given to the vertical eddy tilt magnitude. The exact position of the cyclone core, which is defined as the location of the minimum in $\phi^{\prime}$, at different vertical level is listed in Table 2 (and shown in Fig. 12). The vertical eddy tilt magnitude is estimated from the horizontal distance, measured in degrees, between the cyclone core at a given height and the SLP minimum. For example, during January, the westward tilt with height at the $500 \mathrm{hPa}$ level is larger by a factor of 1.5, and more poleward by almost a factor of 2 , compared to the shoulder months (middle column in Table 2; see also the red dots in Figs. 12b, 12d, and 12f). The distances listed in Table 2 are computed based on the rotated coordinate system and therefore provide estimation of the tilt magnitude. The increase in the 
poleward tilt magnitude with height during January compared to December/November is close to zero in the lower troposphere $(700 \mathrm{hPa}$; left column in Table 2$)$, largest in the midtroposphere $(500 \mathrm{hPa}$; middle column in Table 2), and moderately strong in the upper troposphere $(300 \mathrm{hPa}$; right column in Table 2$)$.

In contrast to the eddy tilt magnitude, the eddy tilt orientation in the rotated coordinate system is fairly constant during the winter season. For example, the eddy tilt orientation estimated from the cyclone core at the 700 and $300 \mathrm{hPa}$ levels (Table 2), is for November, January, and March approximately $149^{\circ}$. Consequently, if we assume that mean baroclinicity vector $\mathbf{B}$ points northward during all seasons, the reduction in the eddy tilt orientation efficiency, seen in a regular geographical coordinate system, results from the change in the eddy propagation direction.

In general, as seen from the composites in Fig. 13, baroclinic conversion is strongest slightly downstream of the surface cyclone center and roughly covers the warm sector of the cyclone. The Lagrangian rate of change in the eddy kinetic energy along surface cyclones is known to be suppressed during midwinter (Schemm and Schneider 2018), and consistently, we find a reduction in baroclinic conversion from the composites (color shading in Fig. 13). The associated eddy heat flux $\mathbf{Q}_{s}$ is suppressed during midwinter (black vectors in Fig. 13) and, in agreement with the northwestward tilt with height of the eddy geopotential isolines, has a more northeastward orientation, while the mean baroclinicity $\mathbf{B}_{s}$ points northward (green vectors in Fig. 12). A close inspection also reveals that the mean baroclinicity $\mathbf{B}_{s}$ points slightly more northwestward during January compared to the shoulder months.

The difference in baroclinic conversion seen between the composites in Fig. 12 is unlikely the result of a greatly varying stage of the cyclone life cycle. The mean cyclone age of cyclones in the composite sample for October is $\tau=1.4$ days; for November, it is $\tau=1.2$ days; for December, it is $\tau=1.3$ days; for January, it is $\tau=$ 1.2 days; for February, it is $\tau=1.3$ days; and for March, it is $\tau=1.5$ days. The cyclones are thus all, on average, in a stage between 1 and 1.5 days after cyclogenesis. This is a period shortly before they experience maximum growth rates (cf. Fig. 11), which is expected to occur after 1.61.9 days of the life cycle (Fig. 11). Because there is only slight variation in cyclone age between the composites, the anomalous poleward tilt with height of the eddy geopotential tubes seen in Fig. 12 (and Table 2) appears to be systematic, in particular because it agrees with what was found from the regression maps (Fig. 8).

Previously, it was found that the reduction in eddy efficiency appears to result from a reduction in the eddy tilt orientation efficiency (Figs. 6 and 9), which is set by the angle between the mean baroclinicity and the eddy heat flux $\left[E_{\mathrm{ff} \nless}=\cos \left(\mathbf{Q}_{s}, \mathbf{B}_{s}\right)\right]$, plus a reduction in the eddy tilt magnitude efficiency (Fig. 6). In the following we explore both changes further using the cyclonecentered composites (Fig. 13).

The eddy tilt orientation efficiency $E_{\mathrm{ff} \nless}$ decreases from November to January (Figs. 13a,c) over the cyclone warm sector and increases again during March (Fig. 13e), by definition due to a larger angle between the eddy heat flux and the mean baroclinicity (Fig. 12d). ${ }^{1}$ This finding is in agreement with a weaker poleward tilt during November and March but a stronger poleward tilt during January. The month-to-month evolution of $E_{\mathrm{ff}} \Varangle$ from the composites is thus in agreement with what is seen in the monthly climatology (Fig. 6) and regression maps (Fig. 8).

The eddy tilt magnitude efficiency $E_{\mathrm{ff} \|}$ makes an additional contribution to the suppression of eddy efficiency (right column; Fig. 13). In general, it is maximized if the vertical tilt with height is neither too strong nor too weak but such that $K_{e}^{\prime}=P_{e}^{\prime}$ (see section 3d for more details), which corresponds to a phase quadrature of the upper and lower-level wave (Davies and Bishop 1994). During January, $E_{\mathrm{ff} \|}$ at $500 \mathrm{hPa}$ is reduced, relative to December, near the surface cyclone center over the warm sector (Figs. 13b,d). Consequently, the vertical eddy tilt with height appears to be too strong between the surface and $500 \mathrm{hPa}$ during January. From January to March (Fig. 13f), there is a mild increase in $E_{\mathrm{ff} \|}$ that is also seen upstream of the surface cyclone center, which is in agreement with its evolution seen in the monthly climatology (right column in Fig. 6). Note that the values of the eddy tilt magnitude seen in the cyclone-centered composites are larger compared to the values seen in the monthly composites. This difference potentially results from the fact that the cyclone-centered composites, in contrast to the monthly climatology, contain a selection of time steps and from the fact that the eddy tilt magnitude in Fig. 13 is computed from the composite-mean eddy geopotential.

To summarize, both the stronger poleward eddy tilt with height, which results in a more eastward-oriented eddy heat flux, and the too strong vertical tilt of the eddy geopotential isolines contribute to the midwinter suppression in eddy efficiency. The baroclinic conversion, shown in Fig. 12, is proportional to the combination of the tilt orientation and the tilt magnitude, which are

\footnotetext{
${ }^{1}$ This finding is independent of the rotation into the propagation direction because both vectors, the eddy heat flux, and the mean baroclinicity are rotated.
} 
a Oct

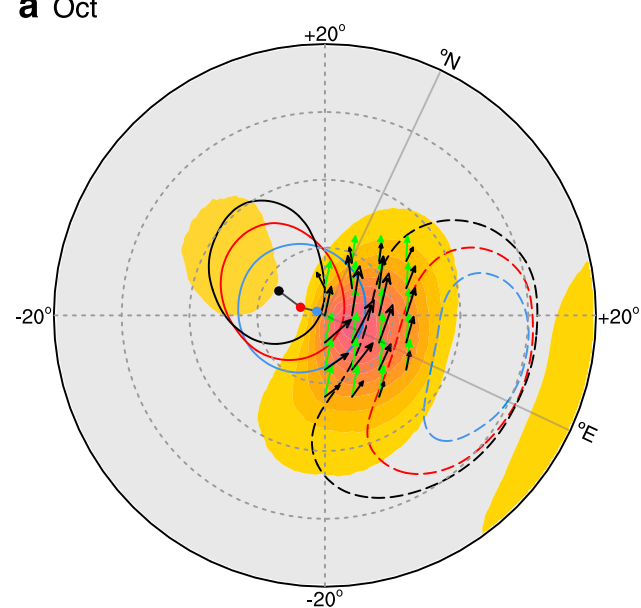

C Dec

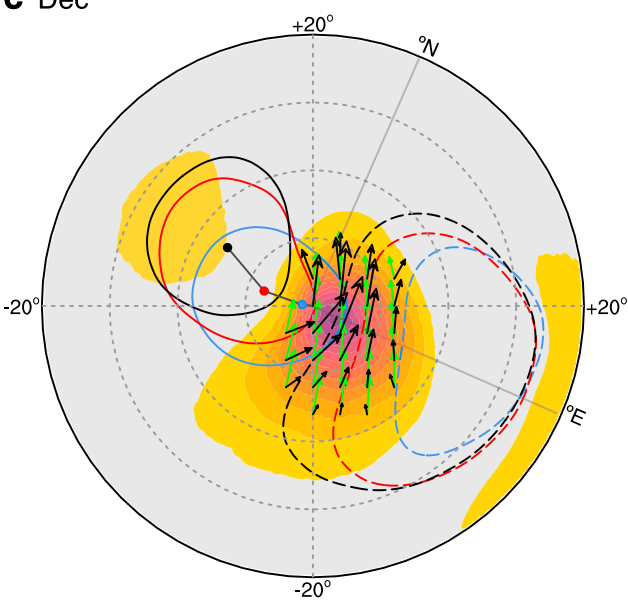

e Feb

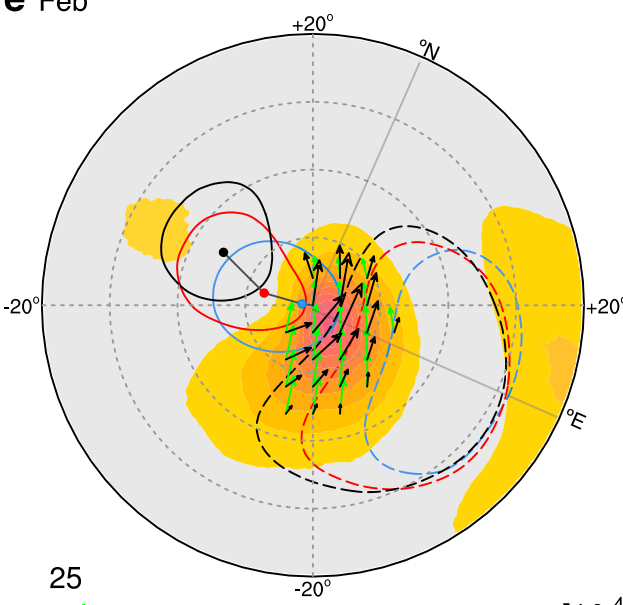

b Nov

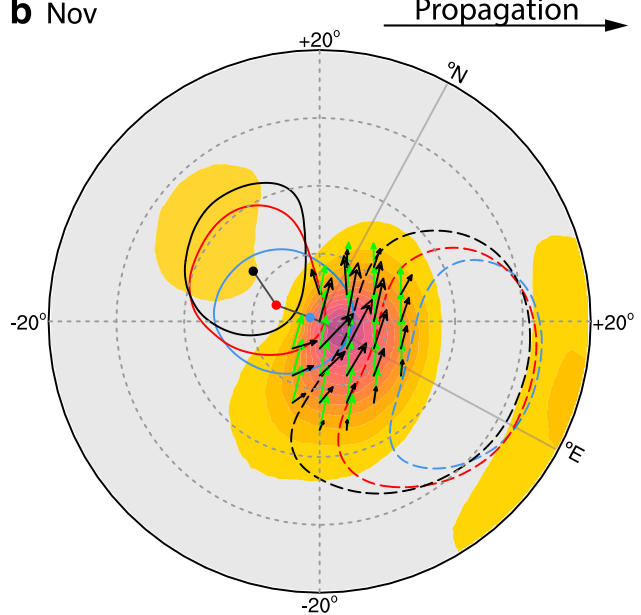

d Jan

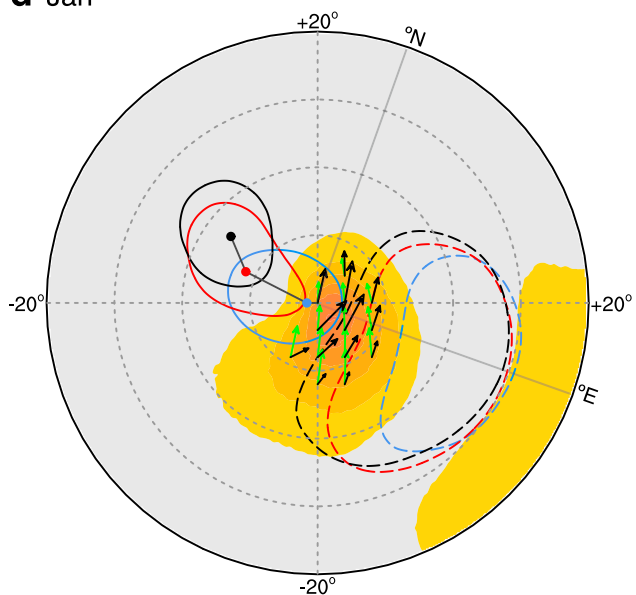

f Mar

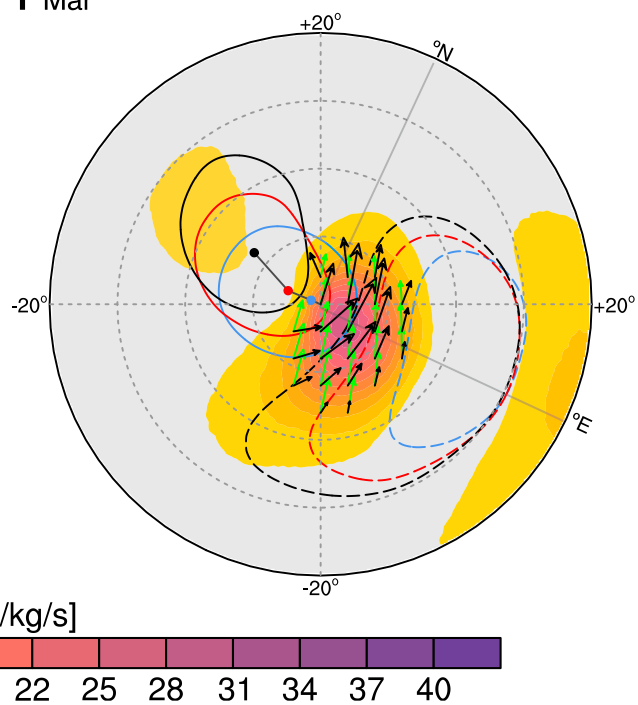

FIG. 12. Cyclone-centered and rotated composites of high-frequency geopotential anomalies at three vertical levels (contours; $700 \mathrm{hPa}$ blue, $500 \mathrm{hPa}$ red, $300 \mathrm{hPa}$ black; solid $-250 \mathrm{~J} \mathrm{~kg}$ and dashed $250 \mathrm{~J} \mathrm{~kg}$ ), corresponding horizontal position of cyclone core (colored dots), baroclinic conversion (color shading), eddy heat flux (black vectors; $\mathrm{m} \mathrm{s}^{-1} \mathrm{~K}^{-1}$ ), and baroclinicity (green vectors; $10^{-4} \mathrm{~s}^{-1}$ ) at $500 \mathrm{hPa}$ for (a) October 
shown in the two columns in Fig. 13 [see Eq. (6)]. The reduction in both the tilt orientation and magnitude occurs over the cyclone warm sector, which is a finding that is not apparent from the regression maps.

Although there is a centering and rotation of all cyclones before the computation of the composites, the remaining differences in the cyclone structures make it difficult to directly compare the orientation of the eddy heat flux on a point-by-point basis. Nevertheless, the difference between the January and December composite is shown in Fig. 14. The difference in the poleward eddy heat flux (green vectors in Fig. 14), truncated to the region of the large difference in eddy efficiency between the composites, shows a less poleward heat flux in January because the eddies are less intense in January and because the eddy meridional wind and temperature are less correlated. By computing the difference between the eddy heat flux normalized by its absolute value, we suppress the difference in eddy amplitude and highlight the difference in eddy structure. The difference between the normalized eddy heat flux (red vectors in Fig. 14) suggests a more eastward-oriented flux during January, relative to December, which is what can be expected from the more poleward-oriented eddy tilt with height. There is even a change in the orientation of the climatological background baroclinicity (black vectors in Fig. 14), suggesting a more westward-oriented background baroclinicity during January, which is also visible in Fig. 6, the regression map (Fig. 9), and Fig. 12. The combination of both orientation changes reduces the eddy tilt orientation efficiency $E_{\mathrm{ff} \nless}$ due to an increase in the angle between the eddy heat flux and the background baroclinicity.

\section{Discussion and summary}

To better understand the midwinter storm-track suppression over the North Pacific, we investigated the efficiency of baroclinic eddy growth. We define the efficiency of baroclinic eddy growth as the product between the eddy heat flux and the mean baroclinicity, which is minus the horizontal potential temperature gradient divided by the static stability. The eddy efficiency is, in contrast to most other eddy measures, independent of the eddy amplitude, which makes it a useful quantity for understanding the effective baroclinic eddy growth. The eddy efficiency is controlled by the eddy vertical tilt orientation and magnitude. For example, a westward-tilting eddy with height produces a northward eddy heat flux. If the eddy heat flux aligns with the mean baroclinicity, the eddy efficiency is maximized and the growing eddy efficiently extracts energy from the mean baroclinicity (see also the schematic in Fig. 1). The baroclinicity magnitude alone, or in other words the Eady growth rate, is not sufficient to explain the effective baroclinic eddy growth, but rather the product between the baroclinicity magnitude and the eddy efficiency. This is also of relevance for understanding future changes in storm tracks.

During midwinter over the North Pacific, the zone of highest baroclinic conversion moves, in tandem with the jet, equatorward. Baroclinic conversion decreases poleward of $40^{\circ} \mathrm{N}$ in a region upstream of and near the core of the main storm track, while it increases equatorward of $40^{\circ} \mathrm{N}$, in a region that is, however, far away from the main storm track. The reduction in baroclinic conversion poleward of $40^{\circ} \mathrm{N}$ is explained by a reduction in the eddy efficiency, which itself reduces due to an anomalous poleward tilt with height for eddies that enter the Pacific trough the northern seeding branch. The anomalous poleward tilt with height results in a more eastward-oriented eddy heat flux, which reduces the eddy efficiency due to of weaker alignment between the eddy heat flux and the baroclinicity. Further, we find a too strong westward tilt with height, which further reduces the eddy efficiency. The reduced eddy efficiency results in weaker baroclinic conversion despite a maximum in the baroclinicity magnitude that, based on a tracking of surface cyclones, is most pronounced during the early and most intense growth phase.

The North Pacific storm track is fed by two branches of upper-level eddies, a northern and southern branch (Chang 2005). The here described mechanism applies mostly to the northern seeding branch and to the region where the seasonal reduction in baroclinic conversion is largest. When upper-level eddies coming from the northern branch reach the entrance of the North Pacific they are constrained to propagate equatorward in midwinter. This constraint could be due to the presence of a

\footnotetext{
(sample size $n=295$; mean cyclone age $\tau=1.4$ days; mean rotation $\left.\angle=-25.4^{\circ}\right)$, (b) November $(n=306$; $\tau=1.2$ days; $\left.\angle=-28.4^{\circ}\right)$, (c) December $\left(n=318 ; \tau=1.3\right.$ days; $\left.\angle=-23.7^{\circ}\right)$, (d) January $(n=294 ; \tau=1.2$ days; $\left.\angle=-19.6^{\circ}\right)$, (e) February $\left(n=270 ; \tau=1.3\right.$ days; $\left.\angle=-23.8^{\circ}\right)$, and (f) March $(n=316 ; \tau=1.5$ days; $\angle=-25.0^{\circ}$ ) for cyclone tracks between $40^{\circ}$ and $55^{\circ} \mathrm{N}$ and $140^{\circ}$ and $165^{\circ} \mathrm{E}$. Composites are rotated into the propagation direction and centered on the minimum sea level pressure. Baroclinic conversion, baroclinicity, and heat flux are estimated from the composite-mean geopotential anomalies.
} 
a Nov

Eddy tilt orientation efficiency

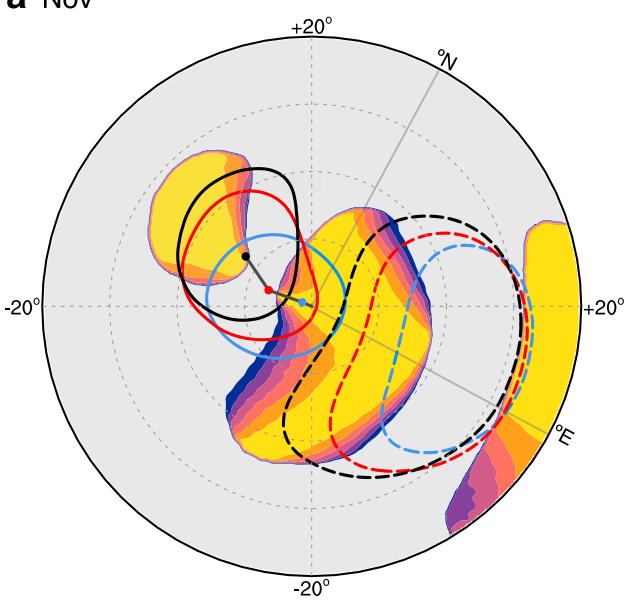

C Jan

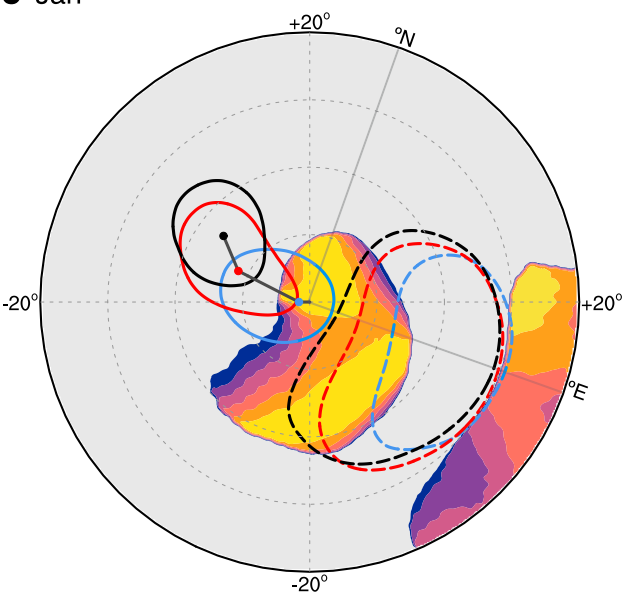

e Mar

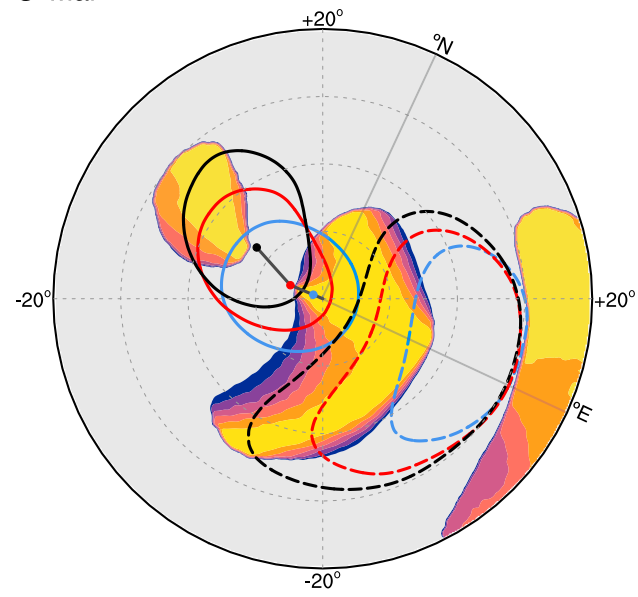

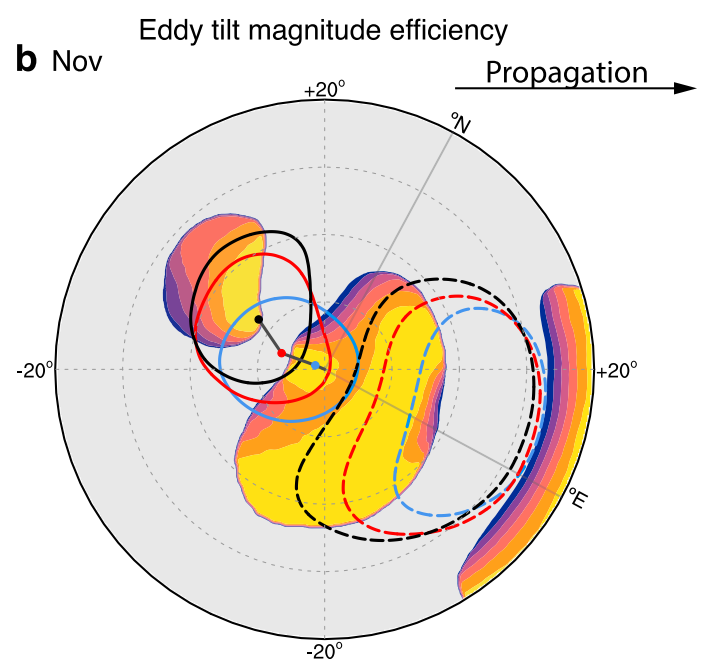

d Jan

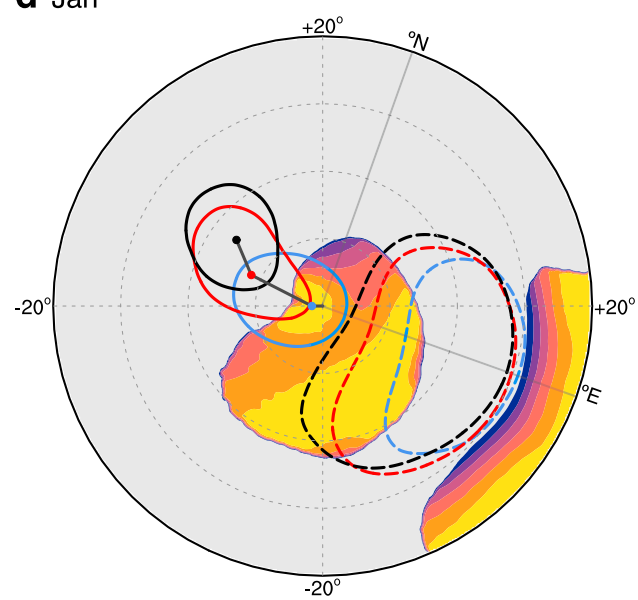

f Mar

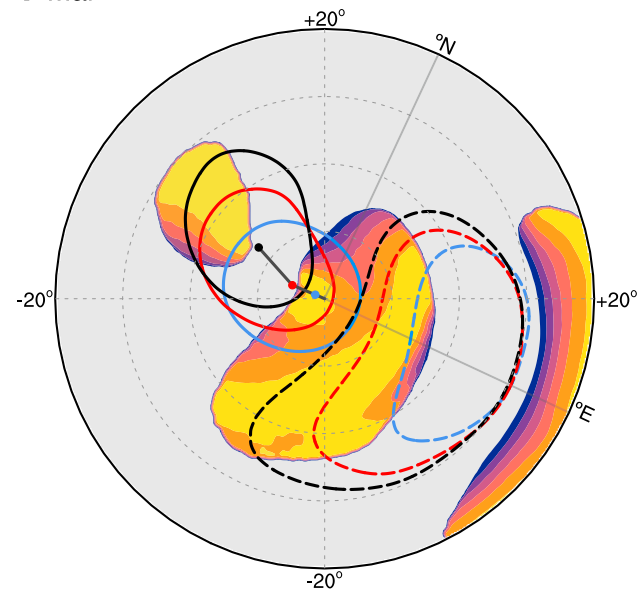

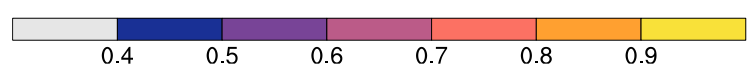

FIG. 13. Cyclone-centered composites of the (left) eddy tilt orientation efficiency $E_{\mathrm{ff} \nless}$ (color shading) and (right) eddy tilt magnitude efficiency $E_{\mathrm{ff} \|}$ for cyclones propagating through $40^{\circ}-55^{\circ} \mathrm{N}, 140^{\circ}-165^{\circ} \mathrm{E}$ during (a),(b) November, (c),(d) January, and (e),(f) March. Also shown are high-frequency geopotential anomalies at three vertical levels (contours; $700 \mathrm{hPa}$ blue, $500 \mathrm{hPa}$ red, $300 \mathrm{hPa}$ black; $-250 \mathrm{~J} \mathrm{~kg}$ ), and the corresponding horizontal position of the cyclone core (colored dots) similar to Fig. 12. 


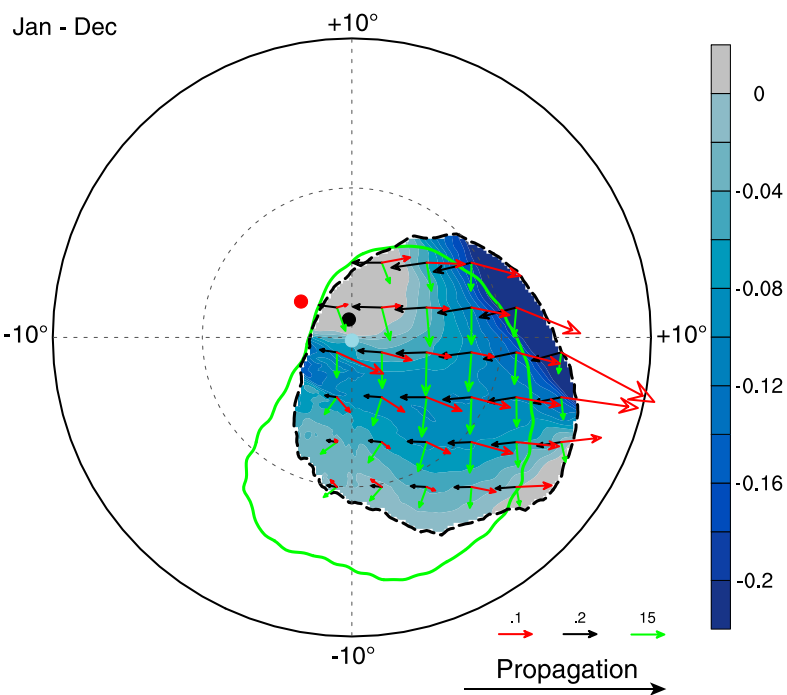

FIG. 14. Difference between the January and December cyclonecentered and rotated composites shown in Figs. 12c and 12d. Shown are changes in eddy heat flux (green vector), normalized eddy heat flux (red vector), background baroclinicity (black vector) and eddy tilt orientation efficiency (color shading). The variables are truncated to the region of the strongest reduction in baroclinic conversion (black dashed contour). The green contour indicates $4 \times$ $10^{-4} \mathrm{~J} \mathrm{~kg}^{-1} \mathrm{~s}^{-1}$ baroclinic conversion during January. The colored dots indicate the difference in the horizontal position of the cyclone core at different vertical levels (light blue $700 \mathrm{hPa}$, red $500 \mathrm{hPa}$, black $300 \mathrm{hPa}$ ). Values below 0.4 are gray masked.

strong subtropical jet located farther equatorward that acts as a waveguide [argument initially provided by Nakamura and Sampe (2002)]. This could be also due to the fact that the maximum baroclinicity is located farther south as it moves in tandem with the jet equatorward in midwinter and baroclinic interaction triggered by eddies coming from the northern branch will necessarily occur farther equatorward. Hence, our findings suggest that during their rapid equatorward propagation in midwinter, synoptic systems triggered by the northern branch acquire an anomalous northwestward tilt with height that reduces the efficiency of baroclinic growth in a region upstream of the main storm track.

Nakamura and Sampe (2002) suggested a distortion of the eddy structure in midwinter leading to a weakened vertical coupling between upper-level eddies and the near-surface baroclinic zone. The authors mentioned that the trapped upper-level eddies along the subtropical jet are not able to efficiently interact with the baroclinic zone situated farther north. Such a distortion would preferentially lead to a southwestward tilt with height of the eddy geopotential isolines and not a northwestward tilt with height as shown in the present paper. Maybe upper-level eddies coming from the southern branch would better fit with Nakamura and Sampe's (2002) suggestion. This leaves room for a further contribution of the southern seeding branch to the suppression.

Our results describe a physically consistent mechanism, which explains reduced storm-track intensity and reduced baroclinic eddy growth in a large-scale flow environment shaped by a strong subtropical jet and high baroclinicity. Consequently, it could be insightful to study changes in the vertical tilt of eddies and related eddy efficiency changes under varying jet regimes in, for example, idealized and zonally symmetric aquaplanet simulations. Further studies are also needed to clarify potential links between the anomalous vertical tilt of eddies and the role of diabatic processes as found by Chang (2001), and to investigate how the character of cyclone life cycles changes during midwinter on the synoptic scale (e.g., warm conveyor belt flow). Further research could also investigate the relative contribution of the southern seeding branch to the suppression and its interplay with the here described mechanism.

Acknowledgments. We acknowledge the helpful comments by three anonymous reviewers and by the editor Hisashi Nakamura.

\section{APPENDIX A}

TABLE 2. Position of the mean cyclone core at three different vertical levels relative to the position of the minimum in sea level pressure for cyclones propagating through $40^{\circ}-55^{\circ} \mathrm{N}, 140^{\circ}-165^{\circ} \mathrm{E}$. The estimation is based on a coordinate system that points into the direction of propagation (see also Fig. 12 and comments in section 6c) and allows for estimating the eddy tilt magnitude.

\begin{tabular}{lccc}
\hline \hline & $700 \mathrm{hPa}$ & $500 \mathrm{hPa}$ & $300 \mathrm{hPa}$ \\
\hline Nov & $0.3^{\circ} \mathrm{N}, 0.7^{\circ} \mathrm{W}$ & $1.2^{\circ} \mathrm{N}, 3.2^{\circ} \mathrm{W}$ & $3.7^{\circ} \mathrm{N}, 4.9^{\circ} \mathrm{W}$ \\
Dec & $0.1^{\circ} \mathrm{N}, 0.8^{\circ} \mathrm{W}$ & $1.1^{\circ} \mathrm{N}, 3.6^{\circ} \mathrm{W}$ & $4.3^{\circ} \mathrm{N}, 6.3^{\circ} \mathrm{W}$ \\
Jan & $0.1^{\circ} \mathrm{N}, 0.8^{\circ} \mathrm{W}$ & $2.3^{\circ} \mathrm{N}, 5.3^{\circ} \mathrm{W}$ & $4.9^{\circ} \mathrm{N}, 6.4^{\circ} \mathrm{W}$ \\
Feb & $0.1^{\circ} \mathrm{N}, 0.8^{\circ} \mathrm{W}$ & $0.9^{\circ} \mathrm{N}, 3.6^{\circ} \mathrm{W}$ & $3.9^{\circ} \mathrm{N}, 6.6^{\circ} \mathrm{W}$ \\
Mar & $0.3^{\circ} \mathrm{N}, 0.7^{\circ} \mathrm{W}$ & $1.0^{\circ} \mathrm{N}, 2.4^{\circ} \mathrm{W}$ & $3.8^{\circ} \mathrm{N}, 4.9^{\circ} \mathrm{W}$ \\
\hline
\end{tabular}

\section{Tendency Equation for Eddy Available Potential Energy}

The high-pass-filtered thermodynamic equation in pressure coordinates reads

$$
\frac{\partial}{\partial t} \theta^{\prime}+\left(\mathbf{v}_{3} \cdot \nabla_{3} \theta\right)^{\prime}=Q^{\prime},
$$

where $\mathbf{v}_{3}$ is the three-dimensional wind velocity. Multiplication with $\theta^{\prime} / S$, where $S=-h^{-1}\left(\partial \theta_{R} / \partial p\right)$ is the static stability, yields for the high-pass-filtered advection term 


$$
\begin{aligned}
\frac{\theta^{\prime}}{S}\left(\mathbf{v}_{3} \cdot \nabla_{3} \theta\right)^{\prime}= & \frac{\theta^{\prime}}{S}\left[\left(\mathbf{v}_{3} \cdot \nabla_{3} \theta\right)-\overline{\left(\mathbf{v}_{3} \cdot \nabla_{3} \theta\right)}\right] \\
= & \frac{\theta^{\prime}}{S}\left[\overline{\mathbf{v}}_{3} \cdot \nabla_{3} \theta^{\prime}+\mathbf{v}_{3}^{\prime} \cdot \nabla_{3} \theta^{\prime}+\mathbf{v}_{3}^{\prime} \cdot \nabla_{3} \bar{\theta}+\overline{\mathbf{v}}_{3} \cdot \nabla_{3} \bar{\theta}\right. \\
& \left.-\overline{\left(\mathbf{v}_{3} \cdot \nabla_{3} \theta\right)}\right] \\
= & \frac{1}{S}\left(\mathbf{v}_{3} \cdot \nabla_{3} \frac{\theta^{\prime 2}}{2}\right)+\frac{1}{S} \theta^{\prime}\left(\mathbf{v}_{3}^{\prime} \cdot \nabla_{3} \bar{\theta}\right)+\frac{\theta^{\prime}}{S}\left[\overline{\mathbf{v}}_{3} \cdot \nabla_{3} \bar{\theta}\right. \\
& \left.-\overline{\left(\mathbf{v}_{3} \cdot \nabla_{3} \theta\right)}\right] \\
= & \nabla \cdot\left(\mathbf{v} P_{e}^{\prime}\right)+\frac{1}{S} \frac{\partial}{\partial p}\left(\omega \frac{\theta^{\prime}}{2}\right)+\frac{1}{S} \theta^{\prime}\left(\mathbf{v}^{\prime} \cdot \nabla \bar{\theta}\right) \\
& +\frac{1}{S} \theta^{\prime} \omega^{\prime} \frac{\partial \theta}{\partial p}-R_{P_{e}},
\end{aligned}
$$

where the residual is $R_{P_{e}}=\left(\theta^{\prime} / S\right)\left[\overline{\left(\mathbf{v}_{3} \cdot \nabla \theta\right)}-\overline{\mathbf{v}}_{3} \cdot \nabla_{3} \bar{\theta}\right]$ and $\nabla_{3} \bar{\theta}=\left[(\partial \bar{\theta} / \partial x) ;(\partial \bar{\theta} / \partial y) ;\left(\partial \theta_{R} / \partial p\right)\right]$. Using the definitions of the scale height $h=\left[(R / P)\left(p / p_{0}\right)^{R / c_{p}}\right]$, the static stability $S=-h^{-1}\left(\partial \theta_{R} / \partial p\right)$, and potential temperature $\theta^{\prime}=-h^{-1}\left(\partial \phi^{\prime} / \partial p\right)$, the fourth term on the righthand side becomes the internal baroclinic conversion, $\left[(1 / S) \theta^{\prime} \omega^{\prime}\left(\partial \theta_{R} / \partial p\right)\right]=\omega^{\prime}\left(\partial \phi^{\prime} / \partial p\right)$, and we obtain Eq. (2) when combining Eq. (A2) with Eq. (A1) and neglecting $Q^{\prime}$. For the last step it is also assumed that the reference potential temperature varies only with height.

\section{APPENDIX B}

\section{Tendency Equation for Eddy Kinetic Energy}

The high-pass-filtered horizontal primitive equation in pressure coordinates reads

$$
\frac{\partial}{\partial t} \mathbf{v}^{\prime}+\left(\mathbf{v}_{3} \cdot \nabla_{3} \mathbf{v}\right)^{\prime}=-f \mathbf{k} \times \mathbf{v}^{\prime}-\nabla \phi^{\prime}+\mathbf{F}^{\prime},
$$

neglecting frictional forces and multiplying with $\mathbf{v}^{\prime}$ yields

$$
\frac{\partial}{\partial t} K_{e}^{\prime}+\mathbf{v}^{\prime} \cdot\left(\mathbf{v}_{3} \cdot \nabla_{3} \mathbf{v}\right)^{\prime}=-\mathbf{v}^{\prime} \cdot \nabla \phi^{\prime} .
$$

The advection term can be expressed as

$$
\begin{aligned}
\mathbf{v}^{\prime} \cdot\left(\mathbf{v}_{3} \cdot \nabla_{3} \mathbf{v}\right)^{\prime}= & \mathbf{v}^{\prime} \cdot\left[\left(\mathbf{v}_{3} \cdot \nabla_{3} \mathbf{v}\right)-\overline{\left(\mathbf{v}_{3} \cdot \nabla_{3} \mathbf{v}\right)}\right] \\
= & \mathbf{v}^{\prime} \cdot\left[\mathbf{v}_{3}^{\prime} \cdot \nabla_{3} \mathbf{v}^{\prime}+\overline{\mathbf{v}}_{3} \cdot \nabla_{3} \mathbf{v}^{\prime}+\mathbf{v}_{3}^{\prime} \cdot \nabla \overline{\mathbf{v}}\right. \\
& \left.+\overline{\mathbf{v}}_{3} \cdot \nabla_{3} \overline{\mathbf{v}}-\overline{\left(\mathbf{v}_{3} \cdot \nabla_{3} \mathbf{v}\right)}\right] \\
= & \mathbf{v}_{3}^{\prime} \cdot \nabla_{3} K_{e}^{\prime}+\overline{\mathbf{v}}_{3} \cdot \nabla_{3} K_{e}^{\prime}+\mathbf{v}^{\prime} \cdot\left(\mathbf{v}_{3}^{\prime} \cdot \nabla_{3} \overline{\mathbf{v}}\right)-R_{K_{e}} \\
= & \nabla \cdot\left(\mathbf{v} K_{e}^{\prime}\right)+\frac{\partial}{\partial p}\left(\omega K_{e}^{\prime}\right)+\mathbf{v}^{\prime} \cdot\left(\mathbf{v}_{3}^{\prime} \cdot \nabla \overline{\mathbf{v}}\right)-R_{K_{e}},
\end{aligned}
$$

where $R_{K_{e}}=\mathbf{v}^{\prime} \cdot\left(\overline{\mathbf{v}_{3} \cdot \nabla \mathbf{v}}-\overline{\mathbf{v}}_{3} \cdot \nabla_{3} \overline{\mathbf{v}}\right)$. Using the continuity equation, $\nabla \cdot \mathbf{v}=-(\partial \omega / \partial p)$, the pressure work term can be expressed as

$$
-\mathbf{v}^{\prime} \cdot \nabla \phi^{\prime}=-\nabla \cdot\left(\mathbf{v}^{\prime} \phi^{\prime}\right)-\frac{\partial}{\partial p}\left(\omega^{\prime} \phi^{\prime}\right)+\omega^{\prime} \frac{\partial \phi^{\prime}}{\partial p},
$$

where the first two terms on the right-hand side correspond to the geopotential flux and the third to the internal baroclinic conversion. The horizontal flux is further reduced to convergence of the ageostrophic geopotential flux $-\nabla \cdot\left(\mathbf{v}_{a}^{\prime} \phi^{\prime}\right)$. Introducing Eqs. (B3) and (B4) in Eq. (B2) and neglecting $\mathbf{F}^{\prime}$ yields Eq. (1).

\section{REFERENCES}

Afargan, H., and Y. Kaspi, 2017: A midwinter minimum in North Atlantic storm track intensity in years of a strong jet. Geophys. Res. Lett., 44, 12511-12 518, https://doi.org/10.1002/ 2017 GL075136.

Booth, J. F., L. Thompson, J. Patoux, and K. A. Kelly, 2012: Sensitivity of midlatitude storm intensification to perturbations in the sea surface temperature near the Gulf Stream. Mon. Wea. Rev., 140, 1241-1256, https://doi.org/10.1175/MWR-D11-00195.1.

Caballero, R., and J. Hanley, 2012: Midlatitude eddies, storm-track diffusivity, and poleward moisture transport in warm climates. J. Atmos. Sci., 69, 3237-3250, https://doi.org/10.1175/JAS-D12-035.1.

Cai, M., and M. Mak, 1990: On the basic dynamics of regional cyclogenesis. J. Atmos. Sci., 47, 1417-1442, https://doi.org/ 10.1175/1520-0469(1990)047<1417:OTBDOR >2.0.CO;2.

Chang, E. K. M., 2001: GCM and observational diagnoses of the seasonal and interannual variations of the Pacific storm track during the cool season. J. Atmos. Sci., 58, 1784-1800, https:// doi.org/10.1175/1520-0469(2001)058<1784:GAODOT > 2.0.CO;2.

- 2005: The impact of wave packets propagating across Asia on Pacific cyclone development. Mon. Wea. Rev., 133, 1998-2015, https://doi.org/10.1175/MWR2953.1.

— - and S. Song, 2006: The seasonal cycles in the distribution of precipitation around cyclones in the western North Pacific and Atlantic. J. Atmos. Sci., 63, 815-839, https://doi.org/10.1175/JAS3661.1. , and P. Zurita-Gotor, 2007: Simulating the seasonal cycle of the Northern Hemisphere storm tracks using idealized nonlinear storm-track models. J. Atmos. Sci., 64, 2309-2331, https://doi.org/10.1175/JAS3957.1.

_- and Y. Guo, 2011: Comments on "The source of the midwinter suppression in storminess over the North $\mathrm{Pa}$ cific.' J. Climate, 24, 5187-5191, https://doi.org/10.1175/ 2011JCLI3987.1.

— and _ 2012: Is Pacific storm-track activity correlated with the strength of upstream wave seeding? J. Climate, 25, 57685776, https://doi.org/10.1175/JCLI-D-11-00555.1.

_ S. Lee, and K. L. Swanson, 2002: Storm track dynamics. J. Climate, 15, 2163-2183, https://doi.org/10.1175/1520-0442(2002) 015<02163:STD $>2.0 . C O ; 2$.

Charney, J. G., 1947: The dynamics of long waves in a baroclinic westerly current. J. Meteor., 4, 136-162, https://doi.org/10.1175/ 1520-0469(1947)004<0136:TDOLWI>2.0.CO;2. 
Cohen, J., and Coauthors, 2014: Recent Arctic amplification and extreme mid-latitude weather. Nat. Geosci., 7, 627-637, https://doi.org/10.1038/ngeo2234.

Coronel, B., D. Ricard, G. Rivière, and P. Arbogast, 2015: Role of moist processes in the tracks of idealized midlatitude surface cyclones. J. Atmos. Sci., 72, 2979-2996, https://doi.org/10.1175/ JAS-D-14-0337.1.

Davies, H. C., and C. H. Bishop, 1994: Eady edge waves and rapid development. J. Atmos. Sci., 51, 1930-1946, https://doi.org/ 10.1175/1520-0469(1994)051<1930:EEWARD>2.0.CO;2.

Dee, D. P., and Coauthors, 2011: The ERA-Interim reanalysis: Configuration and performance of the data assimilation system. Quart. J. Roy. Meteor. Soc., 137, 553-597, https://doi.org/ 10.1002/qj.828.

Deng, Y., and M. Mak, 2005: An idealized model study relevant to the dynamics of the midwinter minimum of the pacific storm track. J. Atmos. Sci., 62, 1209-1225, https://doi.org/10.1175/ JAS3400.1.

Drouard, M., G. Rivière, and P. Arbogast, 2015: The link between the North Pacific climate variability and the North Atlantic Oscillation via downstream propagation of synoptic waves. J. Climate, 28, 3957-3976, https://doi.org/10.1175/JCLI-D-1400552.1.

Eady, E. T., 1949: Long waves and cyclone waves. Tellus, 1 (3), 3352, https://doi.org/10.3402/tellusa.v1i3.8507.

Francis, J. A., 2017: Why are Arctic linkages to extreme weather still up in the air? Bull. Amer. Meteor. Soc., 98, 2551-2557, https://doi.org/10.1175/BAMS-D-17-0006.1.

Harnik, N., and E. K. M. Chang, 2004: The effects of variations in jet width on the growth of baroclinic waves: Implications for midwinter pacific storm track variability. J. Atmos. Sci., 61, 23 40, https://doi.org/10.1175/1520-0469(2004)061<0023:TEOVI $\mathrm{J}>2.0 . \mathrm{CO} ; 2$.

Harvey, B. J., L. C. Shaffrey, and T. J. Woollings, 2014: Equator-topole temperature differences and the extra-tropical storm track responses of the CMIP5 climate models. Climate Dyn., 43, 1171-1182, https://doi.org/10.1007/s00382-013-1883-9.

James, I. N., 1987: Suppression of baroclinic instability in horizontally sheared flows. J. Atmos. Sci., 44, 3710-3720, https://doi.org/ 10.1175/1520-0469(1987)044<3710:SOBIIH>2.0.CO;2.

Lachmy, O., and N. Harnik, 2014: The transition to a subtropical jet regime and its maintenance. J. Atmos. Sci., 71, 1389-1409, https://doi.org/10.1175/JAS-D-13-0125.1.

Laîné, A., and Coauthors, 2009: Northern Hemisphere storm tracks during the last glacial maximum in the PMIP2 oceanatmosphere coupled models: Energetic study, seasonal cycle, precipitation. Climate Dyn., 32, 593-614, https://doi.org/10.1007/ s00382-008-0391-9.

Lapeyre, G., and I. M. Held, 2003: Diffusivity, kinetic energy dissipation, and closure theories for the poleward eddy heat flux. J. Atmos. Sci., 60, 2907-2916, https://doi.org/10.1175/15200469(2003)060<2907:DKEDAC > 2.0.CO;2.

Li, C., and D. S. Battisti, 2008: Reduced Atlantic storminess during Last Glacial Maximum: Evidence from a coupled climate model. J. Climate, 21, 3561-3579, https://doi.org/10.1175/ 2007JCLI2166.1.

Lindzen, R. S., and B. Farrell, 1980: A simple approximate result for the maximum growth rate of baroclinic instabilities. J. Atmos. Sci., 37, 1648-1654, https://doi.org/10.1175/15200469(1980)037<1648:ASARFT>2.0.CO;2.

Lorenz, E. N., 1955: Available potential energy and the maintenance of the general circulation. Tellus, 7 (2), 157-167, https:// doi.org/10.3402/tellusa.v7i2.8796.
Mbengue, C., and T. Schneider, 2018: Linking Hadley circulation and storm tracks in a conceptual model of the atmospheric energy balance. J. Atmos. Sci., 75, 841-856, https://doi.org/ 10.1175/JAS-D-17-0098.1.

Michel, C., and G. Rivière, 2014: Sensitivity of the position and variability of the eddy-driven jet to different SST profiles in an aquaplanet general circulation model. J. Atmos. Sci., 71, 349371, https://doi.org/10.1175/JAS-D-13-074.1.

Nakamura, H., 1992: Midwinter suppression of baroclinic wave activity in the Pacific. J. Atmos. Sci., 49, 1629-1642, https://doi.org/ 10.1175/1520-0469(1992)049<1629:MSOBWA > 2.0.CO;2. , and T. Sampe, 2002: Trapping of synoptic-scale disturbances into the North-Pacific subtropical jet core in midwinter. Geophys. Res. Lett., 29, 2002, https://doi.org/10.1029/ 2002GL015535.

Nakamura, N., 1993: An illustrative model of instabilities in meridionally and vertically sheared flows. J. Atmos. Sci., 50, 357-376, https://doi.org/10.1175/1520-0469(1993)050<0357: AIMOII $>2.0 . \mathrm{CO} ; 2$.

Neu, U., and Coauthors, 2013: IMILAST: A community effort to intercompare extratropical cyclone detection and tracking algorithms. Bull. Amer. Meteor. Soc., 94, 529-547, https:// doi.org/10.1175/BAMS-D-11-00154.1.

Novak, L., M. H. P. Ambaum, and R. Tailleux, 2015: The life cycle of the North Atlantic storm track. J. Atmos. Sci., 72, 821-833, https://doi.org/10.1175/JAS-D-14-0082.1.

O'Gorman, P. A., and T. Schneider, 2008: Energy of midlatitude transient eddies in idealized simulations of changed climates. J. Climate, 21, 5797-5806, https://doi.org/10.1175/ 2008JCLI2099.1.

_- 2010: Understanding the varied response of the extratropical storm tracks to climate change. Proc. Natl. Acad. Sci. USA, 107, 19176-19180, https://doi.org/10.1073/ pnas. 1011547107.

Orlanski, I., and J. Katzfey, 1991: The life cycle of a cyclone wave in the Southern Hemisphere. Part I: Eddy energy budget. J. Atmos. Sci., 48, 1972-1998, https://doi.org/10.1175/15200469(1991)048<1972:TLCOAC $>2.0$. CO;2.

Penny, S., G. H. Roe, and D. S. Battisti, 2010: The source of the midwinter suppression in storminess over the North $\mathrm{Pa}$ cific. J. Climate, 23, 634-648, https://doi.org/10.1175/ 2009JCLI2904.1.

— - — , and - 2011: Reply.J. Climate, 24, 5192-5194, https:// doi.org/10.1175/2011JCLI4187.1.

Penny, S. M., D. S. Battisti, and G. H. Roe, 2013: Examining mechanisms of variability within the Pacific storm track: Upstream seeding and jet-core strength. J. Climate, 26, 52425259, https://doi.org/10.1175/JCLI-D-12-00017.1.

PROJ Contributors, 2018: PROJ coordinate transformation software library. Open Source Geospatial Foundation, https://proj4.org/.

Rivière, G., 2009: Effect of latitudinal variations in low-level baroclinicity on eddy life cycles and upper-tropospheric wavebreaking processes. J. Atmos. Sci., 66, 1569-1592, https:// doi.org/10.1175/2008JAS2919.1.

, and A. Joly, 2006: Role of the low-frequency deformation field on the explosive growth of extratropical cyclones at the jet exit. Part II: Baroclinic critical region. J. Atmos. Sci., 63, 1982-1995, https://doi.org/10.1175/JAS3729.1.

_ B. L. Hua, and P. Klein, 2004: Perturbation growth in terms of baroclinic alignment properties. Quart. J. Roy. Meteor. Soc., 130, 1655-1973, https://doi.org/10.1256/qj.02.223.

, S. Berthou, G. Lapeyre, and M. Kageyama, 2018: On the reduced North Atlantic storminess during the last glacial period: 
The role of topography in shaping synoptic eddies. J. Climate, 31, 1637-1652, https://doi.org/10.1175/JCLI-D-17-0247.1.

Schemm, S., and T. Schneider, 2018: Eddy lifetime, number, and diffusivity and the suppression of eddy kinetic energy in midwinter. J. Climate, 31, 5649-5665, https://doi.org/10.1175/ JCLI-D-17-0644.1.

Shaw, T. A., and Coauthors, 2016: Storm track processes and the opposing influences of climate change. Nat. Geosci., 9, 656664, https://doi.org/10.1038/ngeo2783.

Sprenger, M., and Coauthors, 2017: Global climatologies of Eulerian and Lagrangian flow features based on ERA-Interim. Bull. Amer. Meteor. Soc., 98, 1739-1748, https://doi.org/ 10.1175/BAMS-D-15-00299.1.

Steppeler, J., G. Doms, U. Schättler, H. W. Bitzer, A. Gassmann, U. Damrath, and G. Gregoric, 2003: Meso-gamma scale forecasts using the nonhydrostatic model LM. Meteor. Atmos. Phys., 82, 75-96, https://doi.org/10.1007/s00703-001-0592-9.
Wang, J., H.-M. Kim, and E. K. M. Chang, 2017: Changes in Northern Hemisphere winter storm tracks under the background of Arctic amplification. J. Climate, 30, 3705-3724, https://doi.org/10.1175/JCLI-D-16-0650.1.

Wernli, H., and C. Schwierz, 2006: Surface cyclones in the ERA-40 dataset (1958-2001). Part I: Novel identification method and global climatology. J. Atmos. Sci., 63, 2486-2507, https:// doi.org/10.1175/JAS3766.1.

Woollings, T., J. M. Gregory, J. G. Pinto, M. Reyers, and D. J. Brayshaw, 2012: Response of the North Atlantic storm track to climate change shaped by ocean-atmosphere coupling. Nat. Geosci., 5, 313-317, https://doi.org/ 10.1038/ngeo1438.

Yuval, J., H. Afargan, and Y. Kaspi, 2018: The relation between the seasonal changes in jet characteristics and the Pacific midwinter minimum in eddy activity. Geophys. Res. Lett., $\mathbf{4 5}$, 9995-10 002, https://doi.org/10.1029/2018GL078678. 